\title{
WestVirginiaUniversity
}

THE RESEARCH REPOSITORY @ WVU

Graduate Theses, Dissertations, and Problem Reports

2002

\section{ESL students' perceptions of role-play activities}

Flavia Bonella Ribeiro Ramos

West Virginia University

Follow this and additional works at: https://researchrepository.wvu.edu/etd

\section{Recommended Citation}

Ramos, Flavia Bonella Ribeiro, "ESL students' perceptions of role-play activities" (2002). Graduate Theses, Dissertations, and Problem Reports. 718.

https://researchrepository.wvu.edu/etd/718

This Thesis is protected by copyright and/or related rights. It has been brought to you by the The Research Repository @ WVU with permission from the rights-holder(s). You are free to use this Thesis in any way that is permitted by the copyright and related rights legislation that applies to your use. For other uses you must obtain permission from the rights-holder(s) directly, unless additional rights are indicated by a Creative Commons license in the record and/ or on the work itself. This Thesis has been accepted for inclusion in WVU Graduate Theses, Dissertations, and Problem Reports collection by an authorized administrator of The Research Repository @ WVU. For more information, please contact researchrepository@mail.wvu.edu. 
ESL Students' Perceptions of Role-play Activities

Flavia Bonella Ribeiro Ramos

\begin{abstract}
Thesis submitted to the
Eberly College of Arts and Sciences at West Virginia University in partial fulfillment of the requirements

for the degree of
\end{abstract}

Master of Arts
in
Foreign Languages

Susan M. Braidi, Ph. D., Chair

Frank W. Medley, Jr., Ph. D.

Dara G. Shaw, Ed. D.

Department of Foreign Languages

\author{
Morgantown, West Virginia \\ 2002
}

Keywords: Role-play, Students' Perceptions Copyright 2002 Flavia Bonella Ribeiro Ramos 


\section{ABSTRACT \\ ESL Students' Perceptions of Role-play Activities}

\section{Flavia Bonella Ribeiro Ramos}

There has been significant discussion on the use of role-play activities. Proponents of role-play believe that the activity provides learners with opportunities to communicate freely and spontaneously in different situations. However, researchers have also identified issues that may jeopardize the effectiveness of role-plays. Despite the debate, few studies have focused on the students' point of view. The current qualitative study investigated ESL students' perceptions of role-play activities drawing on observations, questionnaires, and interviews. The results showed that the participants recognized several benefits (e.g., improving oral proficiency, acquiring vocabulary, and rehearsing for real-life communication) while also acknowledging some limitations such as artificiality and lack of vocabulary and ideas. 
Dedication

To Etelvo and my parents, Gelço and Onorita 


\section{Acknowledgments}

First, I would like to thank the committee members, who took the time to work with me on this project. I have no words to express my gratitude to Dr. Susan Braidi, who guided and assisted me throughout the whole process. Thanks for helping me in so many ways. Thanks to Dr. Frank Medley for all of his valuable suggestions and patience, and to Dr. Dara Shaw for her comments and for the special attention she has always given me. I would like to let my committee members know that I am really grateful for having had the opportunity to work with such great professionals.

I would also like to thank my husband, Etelvo, for supporting me and giving me constant encouragement. Thanks to my parents and friends for their friendship and understanding. Special thanks to Stacy Fint, who is a great person and a wonderful friend, and to my godmother, Alina, for her important tips.

I would like to express my appreciation to the instructor and the nine students who kindly accepted to take part in this study. Finally, I would like to thank the directors of the Intensive English Program, Helen Huntley and Dara Shaw, for having supported this research project. 
Chapter 1: Introduction .........................................................

Chapter 2: Review of the Literature .......................................... 8

Communicative Competence and Language Teaching ...................... 8

Role-plays: Types and Formats .............................................. 15

Role-play: a Definition ............................................... 18

Strengths and Drawbacks ............................................. 20

Studies on Role-play Activities ........................................ 23

Chapter 3: Design and Methodology ............................................ 31

Research Questions .............................................. 32

Participants ............................................................. 35

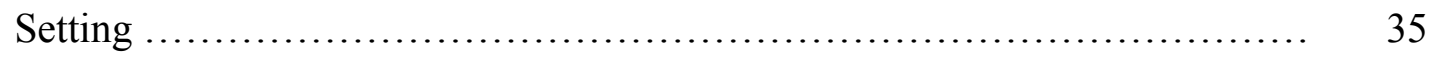

A Qualitative Research Design ...................................... 36

Observation ........................................................... 36

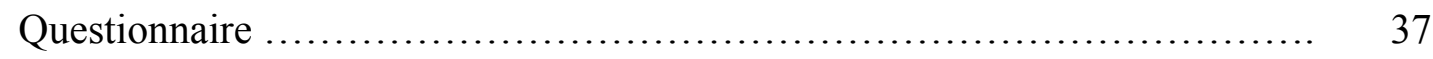

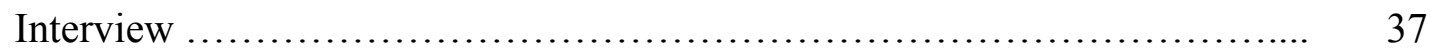

Procedures .............................................................. 38

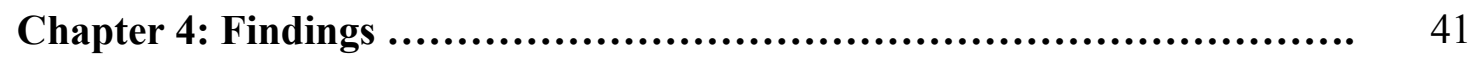

The Participants: a Closer Look ......................................... 41

Recognition of the Benefits ........................................ 53

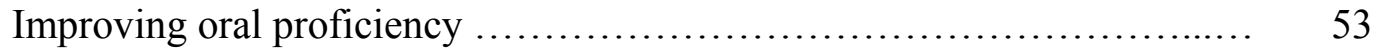

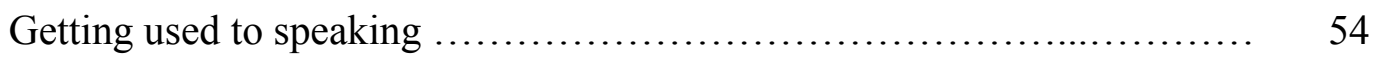

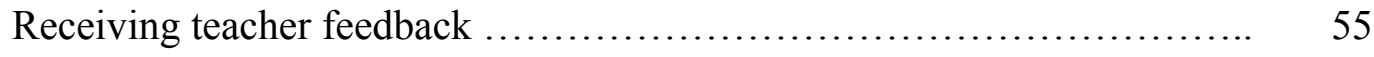




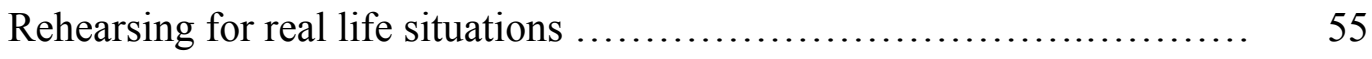

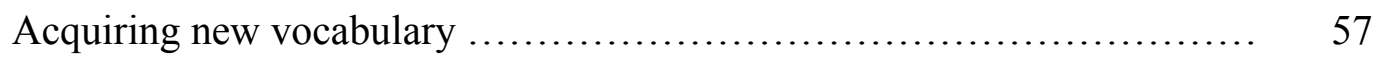

Having fun in class ......................................... 57

Learning from classmates .................................... 58

Recognition of the Limitations ..................................... 60

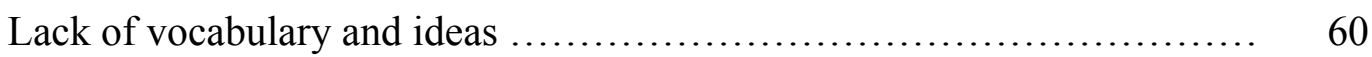

Animosity between students $\ldots \ldots \ldots \ldots \ldots \ldots \ldots \ldots \ldots \ldots \ldots \ldots \ldots \ldots \ldots \ldots \ldots \ldots, 61$

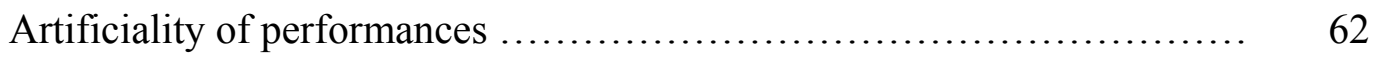

Artificiality of the task ........................................ 63

Feelings and Reactions to Role-play Activities ........................ 65

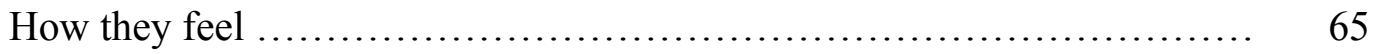

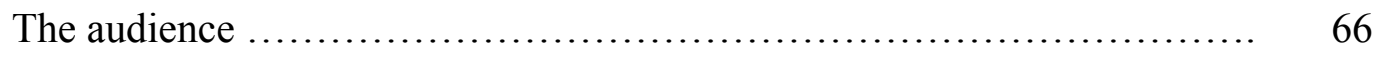

Participants' preferences ........................................ 69

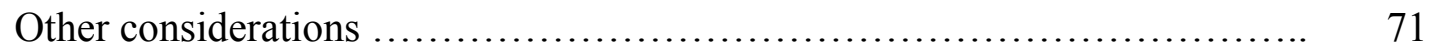

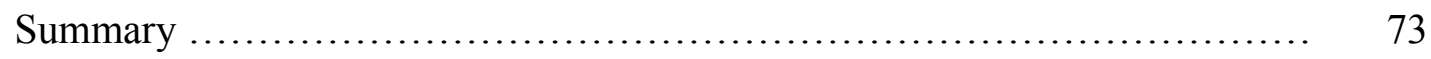

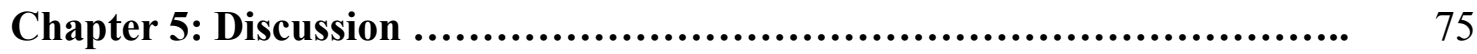

The Positive Aspects ........................................... 75

The Negative Aspects .......................................... 83

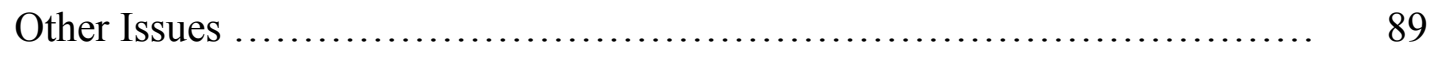

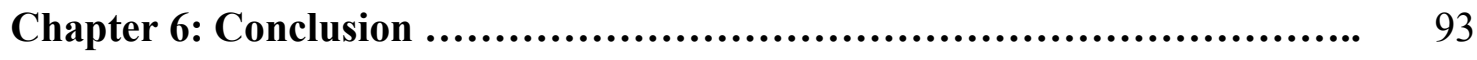

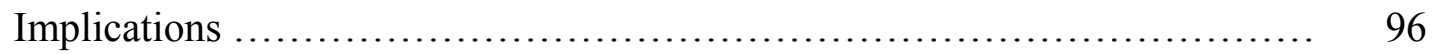

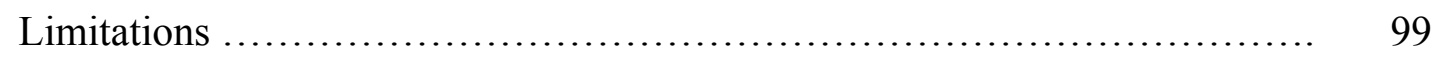

Suggestions for Further Research $\ldots \ldots \ldots \ldots \ldots \ldots \ldots \ldots \ldots \ldots \ldots \ldots \ldots \ldots \ldots . \quad 98$ 


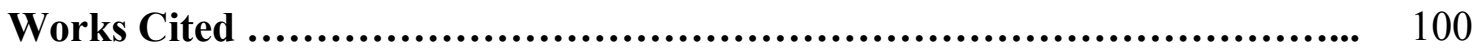

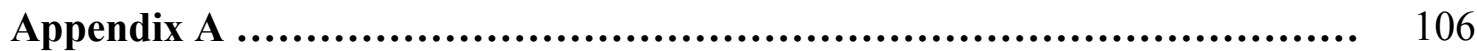

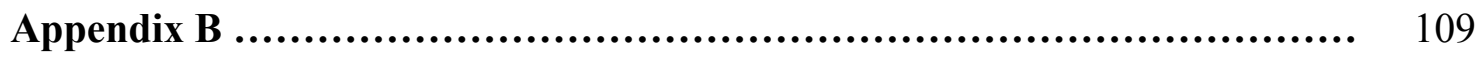

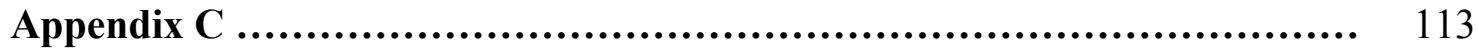

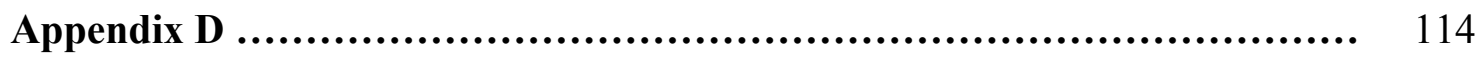

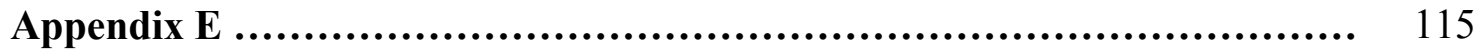

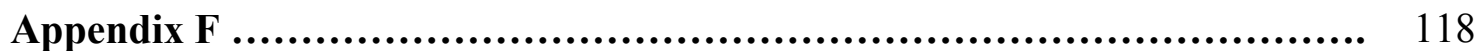




\section{Chapter 1}

Introduction

Although some learners may not have communicative needs when they decide to learn a second language (L2) (Savignon, 1997), English as a second language (ESL) learners typically do have to develop communicative competence. These learners need to use their developing language skills in order to function effectively in the ESL setting. Paulston (1985) claims these students really need to be taught general sociocultural rules in order to be able to negotiate meaning ${ }^{1}$ and interact in socially appropriate ways. Paulston (1985) believes that "life can become unnecessarily complicated without attention to the communicative competence of a language" (p. 20).

Since the term communicative competence was introduced into the language teaching literature, there have been several definitions of its meaning. Rivers (1973) defines communicative competence as simply linguistic interaction, that is, having sufficient command of the target language to express ideas spontaneously. However, Hymes (1972) points out that knowing the linguistic forms of a language will not provide learners with the ability to speak competently. Communicative competence, in Hymes' view, also involves social rules. It means knowing what to say to whom, when, and in what circumstances.

\footnotetext{
${ }^{1}$ Negotiation of meaning has most recently been defined by Long (1996) as "the process in which, in an effort to communicate, learners and competent speakers provide and interpret signals of their own and their interlocutor's perceived comprehension, thus provoking adjustments to linguistic form, conversational structure, message content, or all three, until an acceptable level of understanding is achieved" (p. 418).
} 
Canale and Swain (1980) developed a broader definition, in which communicative competence includes three areas of knowledge and skills. These areas encompass grammatical competence, sociolinguistic competence, and strategic competence. Grammatical competence consists of linguistic competence, the knowledge of vocabulary, pronunciation, spelling, and sentence formation. Sociolinguistic competence is the ability to use language appropriately depending on the social context. Strategic competence consists of the ability to copy verbal and non-verbal strategies that speakers of a language use to communicate. Later, Canale (1983) added discourse competence to the framework suggested by Canale and Swain (1980). This competence “... concerns mastery of how to combine grammatical forms and meanings to have unified spoken and written text in different genres" (Canale, 1983, p. 9).

Although teaching communicative competence is not simple (Paulston, 1985), some pedagogical approaches have been developed to try to devise better ways to help language learners acquire communicative competence (Taylor, 1982). Scarcella and Oxford (1992) believe that for communicative competence to be best taught in ESL programs teachers should "... provide students with exposure to and interaction in the diverse registers they need to know" (p. 80). In their opinion, one of the ways to provide students with opportunities to interact and be exposed to the language they need is by using role-plays in the classroom. According to the authors, role-plays "...bring the outside world into the classroom" (p. 80), and limitations imposed by the classroom are overcome (Littlewood, 1981).

Various definitions of role-play have emerged throughout the years. Littlewood (1981) defines role-playing as a classroom technique in which "a) learners imagine themselves in a situation which could occur outside the classroom; b) learners adopt a 
specific role in this situation; c) learners are asked to behave as if the situation really existed, in accordance with their roles" (p. 49). However, some authors define role-plays as activities in which participants assume roles other than those of themselves (Robinson, 1981; Harmer, 1991; Purcell, 1993). In spite of the role they are playing, "learners must negotiate in the interaction itself as it unfolds, each partner to the other's communicative acts and strategies" (Littlewood, 1981, p. 56).

Much has been said about the advantages of the use of role-plays in the language classroom. The most positive aspect is that role-plays provide students with opportunities for practicing in class the language they need for interacting outside the classroom (Littlewood, 1981; Robinson, 1981; Raz, 1985;). Since learners are able to role-play numerous situations, role-plays can be made relevant to their needs (Scarcella and Oxford, 1992). In addition, once learners identify roles and situations equivalent to reallife, they will be motivated to produce real-life language (Robinson, 1981). According to Raz (1985), "this rehearsal also has the effect of psychological innoculation, reducing anxiety and inhibitions when the learner has the opportunity to use language outside the classroom" (p. 228).

Another benefit of role-playing is learning about cultural differences between the target language and the mother tongue. Purcell (1993) mentions the fact that children, for example, are likely to assume that their first language (L1) and the target language have the same cultural functions, until they are given the chance to discover otherwise. Di Pietro (1981) stresses not only the importance of the functions of a language but also their constraints. He mentions that disagreeing with a police officer about a ticket may be appropriate in some cultures, but it does not suit others. Through role-playing, learners are able to vary language according to the social context and situation (Scarcella, 1979). 
Therefore, different registers and functions are explored as learners progress (Savignon, 1997). Consequently, as Richards (1980) points out, learners become aware of principles that characterize successful communication, which takes place when speakers and hearers can interpret and contribute to each other's utterances.

In the last two decades, some studies have focused on the use and effectiveness of role-plays. Stern (1980) claims that drama and role-plays “...can develop and/or elicit communicative competence in the individual" (p. 87). She suggests that these activities trigger certain psychological factors that promote communication. In her investigation, she also noticed that both shy and more extroverted students benefited from drama and role-plays. Raz (1985) also finds role-plays to be an effective technique. The study conducted with 200 Israeli students proved that role-plays affect communicative competence, motivation, and foreign language learners positively. Similar results were obtained by Su (1990) when she investigated and evaluated the effectiveness of role-play activities on Chinese students of English as a foreign language (EFL). The researcher reports that the learners who were taught through role-play had higher scores on English proficiency tests, especially on the oral test. These students also became more confident and less inhibited in speaking English, as well as more willing to take part in interactions in English. Some of the disadvantages of the technique pointed out by the researcher are the noise level, the difficulty some students have in role-playing certain roles, and the fact that more advanced students monopolize most speaking opportunities.

Although role-plays have been widely used in language teaching, many authors have identified several drawbacks to the activity. One of the negative aspects of roleplays is related to the artificiality inherent to the task. Scarcella (1979) mentions that during role-play situations learners do not produce the same language they would in a 
real-life situation, which is a more natural and relaxed setting. Piper and Piper (1983), Piper (1984), and Al-Arish (1994) show concern about the lack of reality in roles assigned to learners during role-plays. They argue that role-plays are unsuccessful because the roles assigned do not reflect learners' experiences and needs. Moreover, Taylor (1982) claims that "students do not appear to be as likely to engage not only their language but their whole selves as fully in contrived simulations, which are essentially uncompelling, as they are when they have a stake in the outcome of their endeavors" (p. 36).

Critics also raise the issue of audience. Robinson (1981) finds it difficult to involve the rest of the class while a small group of learners act out their roles. Al-Arish (1994) points out that the audience plays a negative role since real communication does not usually take place in front of a crowd. Furthermore, Smith (1986) claims that more successful learners tend to dominate the interaction while the rest of the class listens to their ungrammatical sentences. In addition, Widdowson (1987) argues that learners may not be able to transfer what they have learned in class to real contexts in order to deal successfully with language demands. Their performance is restricted to the limited situations practiced in class. Other areas of concern are correction, which stops the flow of language and actions (Robinson, 1981); and the fact that role-plays may lead to embarrassment (Piper \& Piper, 1983; Surplus, 1983). According to Smith (1986), promoters of role-play “...may have set their goals too high” (p. 17), and role-playing may not be as effective as the theory suggests.

Even though many authors have discussed the advantages and disadvantages of role-play activities, it appears that few studies have taken the learners' perspectives into account. Most reports on how students perceive role-play tasks are based on observation 
and on the intuitive sense of teachers and researchers. Since studies have shown that teachers' and learners' views of classroom tasks do not always match (Nunan, 1986; Block, 1994), I find it important to focus on the learners' perceptions of role-play activities. Therefore, the purpose of the current study is to investigate how ESL learners perceive the use of role-play tasks in the classroom. In what ways do they believe roleplays facilitate interaction outside the classroom?

In addition to the lack of empirical evidence of the students' perceptions of roleplay activities, two other reasons triggered the present investigation. First, the researcher is interested in learning if ESL learners view classroom activities as facilitators of interaction in the real world. Since role-plays, as Littlewood (1981) states, are activities that “... approximate more closely to the kind of communication encountered outside the classroom, where language is not only a function instrument, but also a form of social behavior"'(p. 43), this activity seemed ideal for the study. Second, according to Al-Arish (1994), role-playing might be losing its function in communicative language teaching (CLT) since not much has been published about the activity in the 1990s, which accounts for the scarce number of recent articles and books on the topic. However, the activity still plays a role in many textbooks currently used in ESL and EFL classrooms. These titles include Sound ideas by Fragiadakis and Maurer (1995), All clear! by Fragiadakis (1997), New interchange by Richards, Hull, and Proctor (1997), and Talk it through by Kozyrev and Baker (2001). Therefore, role-plays are still part of the activities proposed to students in language classrooms.

In order to assess the learners' perspectives, I decided to carry out a qualitative project. The choice of qualitative research is based on the statement by Marshall and Rossman (1999) that “...qualitative research is pragmatic, interpretive, and grounded in 
the lived experiences of people" (p. 2). As the focus of the research is on the learners' view, there is a need for the research to "...understand human actions ... and the meaning participants attribute to those actions - their thoughts, feelings, beliefs, values, and assumptive worlds" (p. 57). For these reasons, a qualitative research design seemed to be the ideal one.

The present study is organized as follows. In chapter 2, a review of the literature related to role-play activities is presented. This chapter includes an account of communicative competence in language teaching. It also contains a definition of roleplay and differences between role-plays and other similar activities. In addition, in the review of the literature the positive and the negative qualities attributed to the use of roleplays in language classrooms are addressed. In chapter 3 , I provide a detailed description of the participants, as well as the design and methodology of the study. The results obtained from the questionnaire, student and teacher interviews, and class observations are presented in chapter 4 . Next, these findings are discussed in chapter 5 , and a conclusion is presented in chapter 6 . 


\section{Chapter 2}

Review of the Literature

This chapter consists of a review of the existing literature on role-play activities, developed as follows: first, it contains a description of the theory of communicative competence as defined by Canale and Swain (1980) followed by its implications for language teaching. Next, different types and formats of role-play activities are defined. The activity is then differentiated from other similar activities used in language classrooms, and a definition of role-play is provided. The following section deals with the pros and cons attributed to the activity during the years it has been used. Finally, empirical studies that have investigated the use of role-plays are presented, and their findings are discussed.

\section{Communicative Competence and Language Teaching}

In the late 1960s, linguists began to question the theoretical assumptions underlying the current standard structural theories of language teaching at the time. Situational Language Teaching in Britain and Audiolingualism in the United States failed to account for fundamental dimensions of language such as the creativity and uniqueness of individual sentences, and the functional and communicative potential of language. Applied linguists decided that it was time for language teaching to focus on communicative ability and not on the mastery of structures. Language learning could no longer be seen as habit formation (Richards \& Rodgers, 1986).

In this context, CLT was born. According to Howatt (1984) its underlying philosophy holds that:

Learning how to speak a new language is not a rational process 
which can be organized in a step-by-step manner following graded syllabuses of new points to learn, exercises, and explanations. It is an intuitive process for which human beings have a natural capacity that can be awakened provided that the proper condition exists (p. 192).

The new approach, which is learner-centered and experience-based in nature, views language as communication. The aims of CLT are to "...develop procedures for teaching the four language skills that acknowledge the independence of language and communication and to make communicative competence the goal of language teaching" (Richards \& Rodgers, 1986, p. 66).

The term communicative competence was introduced by Hymes in the 1960s. While some experts such as Rivers (1973) view communicative competence as the ability to carry out linguistic interaction in the target language, Hymes focuses on language in actual performance. He views language as social interaction; therefore, he advocates the integration of a linguistic theory and a theory of communication and culture. According to Hymes (1972), the acquisition of communicative competence should enable a person to use language appropriately according to:

1. Whether (and to what degree) something is formally possible;

2. Whether (and to what degree) something is feasible in virtue of the means of implementation available;

3. Whether (and to what degree) something is appropriate (adequate, happy, successful) in relation to a context in which it is used and evaluated; 4. Whether (and to what degree) something is in fact done, actually performed, and what its doing entails (p. 281). 
Although Hymes' (1972) ideas of communicative competence were extremely important for the field, it was Savignon (1972), who first brought it to the attention of the foreign language community. Later, Canale and Swain (1980) proposed a classroomoriented model of communicative competence. Based on the research of communicative approaches, they came up with a framework designed to be applied to the four main areas of second language teaching, that is, syllabus design, teaching methodology, teacher training, and materials development. This framework, which was later refined by Canale (1983), consists of four areas of competence: grammatical competence, sociolinguistic competence, discourse competence, and strategic competence. Savignon (1983) supports this framework.

Grammatical competence refers to the mastering of verbal and non-verbal language codes. This dimension of communicative competence includes knowledge of lexical items and rules of morphology, syntax, semantics, and phonology. The acquisition of grammatical competence enables learners to understand and accurately express the literal meaning of utterances. Therefore, it is an important concern for communicative approaches. However, grammatical competence is not more or less important than the other three competence areas included in Canale and Swain's framework.

Sociolinguistic competence is the skill area concerned with "...the extent to which utterances are produced appropriately in different sociolinguistic contexts depending on contextual factors such as the status of the participants, purposes of the interaction, and norms and conventions of the interaction" (Canale, 1983, p. 7). The appropriate use of language includes both appropriateness of meaning and form. Acquiring the knowledge of sociocultural rules is essential for learners to distinguish the literal meaning of utterances from the speaker's intentions. 
Discourse competence is related to the knowledge of combining grammatical forms and meanings in order to obtain a cohesive and coherent spoken or written text in different genres. There may be overlaps between discourse competence and grammatical rules (when dealing with cohesion) as well as sociocultural rules (when dealing with coherence). Nevertheless, only discourse competence will refer to notions such as the organizational patterns of discourse.

Strategic competence includes the mastery of both verbal and non-verbal strategies that are used to compensate for breakdown in communication or enhance the effectiveness of communication. These strategies may be related to grammatical competence (e.g., paraphrasing) and sociolinguistic competence (e.g., shifts in register and style). Strategic competence seems to be more helpful at the beginning stages. As learners develop their second language proficiency, it is very likely that their need for certain strategies changes.

Bachman (1990) proposes a new model of communicative competence, which he calls language competence. In this newer view, language competence is subdivided into two categories: organization competence and pragmatic competence. The former includes grammatical competence and textual competence (formerly discourse competence). It is related to the rules and systems that determine what can be done with the forms of a language both at the sentence and text levels. The latter, pragmatic competence, involves illocutionary and sociolinguistic competence. The first concerns the sending and the receiving of intended meanings, and the second deals with cultural aspects of the language as well as considerations such as politeness, formality, metaphors, and register. Bachman considers strategic competence a different unit of communicative language 
ability. This competence enables the speaker to choose, among many other possible options, the right words, phrases, and ways to negotiate meaning.

Developing communicative competence is now taken to be the objective of language teaching. While Savignon (1997) states that not all students who come to English programs have communicative needs, Scullard (1996) maintains that students' most important goals are learning how to speak and understanding the culture. Their main interest is to develop communicative competence. Since course syllabi are influenced by learners' needs when undertaking a language course (Nunan, 1988), producing speakers who can communicate appropriately in the target language has become one of the main goals in teaching (Richards \& Rodgers, 1986, 2001).

According to Canale and Swain (1983), the aim of teaching communicative competence is to facilitate the integration of the four skill areas. These four components of communicative competence are equally crucial to successful communication. However, Savignon (1983) claims that linguistic accuracy is one of the major constituents of interaction. Canale (1983) and Paulston (1985) argue for the importance of social cultural rules and their role in interactions. Canale (1983) claims that "sociolinguistic competence is crucial in interpreting utterances for their 'social meaning' for example, communicative function and attitude, when it is not clear from the literal meaning of utterances or from non-verbal cues" (p. 8). Paulston and Bruder (1976) note that people may be considered rude or tactless when speaking a second language due to the fact that they do not share the same social rules, which vary from culture to culture. Paulston's (1985) idea of communicative competence, which is quite restricted, focuses only on sociocultural rules for language use. She provides plenty of examples of how the 
lack of sociocultural rules may cause problems for individuals functioning in the target culture.

Paulston also acknowledges some problems related to teaching communicative competence. She mentions that English is also spoken in Britain and Australia, for example, and their way of using the language cannot be ignored. This raises the question of which sociocultural rules should be taught. In addition, she talks about countries like Singapore, where English is considered a second language. People in that country use English due to economic and political reasons, and not because they are fond of the United States or England. In this case, people will continue to speak English with the sociocultural rules of their native tongue. There is no point in teaching people from Singapore to behave in ways that reflect U.S. values. However, the same is not true for ESL students who are living in the culture in which the target language is spoken. These students have to learn general American English rules of language use to interact and negotiate meaning appropriately in the different social contexts in a U.S. setting. For instance, according to Paulston, Latin American students need to be taught not only how to thank in English, but also that they should say "thank you" only once. The Japanese need to learn forms to turn down requests and also whose requests they may turn down in a U.S. environment, which is extremely different from the Japanese one.

Although researchers have not yet established the actual role of interaction in the development and internalization of L2 knowledge (Gass, Mackey \& Pica, 1998), interaction seems to play a major role in the development of communicative competence. Lee and VanPatten (1995) stress the importance of providing students with opportunities to engage in communicative interactions in the classroom as they would outside the classroom. They need to use language to interpret, express, and negotiate meaning. 
Littlewood (1981) and Rivers (1978) mention the importance of having students use the L2 for normal purposes and in meaningful social contexts. Rivers also claims that acquisition will take place when learners find themselves in situations in which they are on their own, free to interact as equal partners. Scarcella and Oxford (1992) add that ESL learners need to take part in interactions that promote language use with more knowledgeable peers and others who have more linguistic resources. In brief, the development of communicative competence takes place when learners are motivated to communicate and experience communication (Savignon, 1983).

In order to promote the acquisition of communicative competence, CLT has developed a number of activities that provide students with the opportunity and motivation to communicate and the purpose for doing so. One of these activities involving varied use of language and allowing students to arrive at a degree of language autonomy is role-playing (Harmer, 1991). According to Paulston and Bruder (1976), roleplay activities contribute to the development of communicative competence because learners have to get the meaning across in a socially acceptable way. Moreover, the activity contains culturally relevant information. Rivers (1981) views role-plays as opportunities for learners to try to use what they have learned in communication situations. Maley (1980), Littlewood (1981), and Scarcella and Oxford (1992) value the activity because it allows teachers to bring reality into the classroom, and it exposes students to different registers and more varied forms of interaction. Since role-play activities have features that lead to communicative competence development, they have been widely used in CLT language classrooms. 


\section{Role-plays: Types and Formats}

Researchers, textbook writers, and teachers have used the term role-play in different ways. Paulston and Bruder (1976) refer to role-play as “...exercises where the student is assigned a fictitious role from which he has to improvise some kind of behavior toward the role characters in the exercise" (p. 70). For the authors, two basic features of role-play are improvisation and fictitious roles. Guntermann (1980), Harmer (1981), Robinson (1981), and Purcell (1991) also describe role-plays as activities in which students are asked to act upon an imaginary situation assuming a different identity. However, Littlewood (1981) defines role-play as an activity in which "learners are asked to imagine themselves in a situation which could occur outside the classroom; to adopt a specific role in this situation; and to behave as if the situation really existed" (p. 49). In his definition, Littlewood mentions that learners may be asked to act as themselves, and other times, they may have to adopt a simulated identity. Similarly, Holden (1981) and Errington (1997) hold that role-playing consists of playing yourself or somebody else in an imaginary situation.

Littlewood (1981) presents examples of role-play activities that are grouped according to the nature of control exercised by the teacher. The activities are part of a continuum ranging from pre-communicative to communicative activities. The former is defined as activities that “...aim to equip the learner with some of the skills required for communication, without actually requiring him to perform communicative acts" (p. 8). The latter consists of activities in which "...the learner uses the linguistic repertoire he has learnt, in order to communicate specific meanings for specific purposes" (p. 17). Four types of role-play are part of this continuum: role-playing controlled through cued 
dialogues, role-playing controlled through cues and information, role-playing controlled through situation and goals, and role-playing in the form of debate or discussion.

In role-plays controlled though cued dialogues, each learner receives cues on separate cards. "Two sets of cues must interlock closely" (Littlewood, 1981, p. 52) so that cues can only generate utterances that match cues that follow. Even though learners' creativity is quite limited, this kind of role-play still presents a certain amount of uncertainty and spontaneity inherent to real communication. Learners have to listen to their partners before providing an appropriate response.

In the second activity described, cues and information, only one learner receives detailed cues, while the other is given information that allows him to respond as necessary. It is a more flexible framework, and it suits situations where people need to gather information or obtain a service.

Role-plays controlled through situations and goals are looser structures in which learners have greater control over their interaction. They do not have to express specific meaning that was previously determined. Instead, they have to achieve a goal in a given situation through communication. As the interaction unfolds, learners are supposed to respond spontaneously to their partners' communicative acts and strategies.

The last role-play in Littlewood's continuum “...is a debate or discussion about a real or simulated issue" (p. 57). The prerequisites for the activity are having adequate knowledge about the topic, and having opposite opinions or interests. Learners can either get to a decision or just put the issue to a vote at the end. The interaction is a result of the conflict of opinions. Examples of these kinds of activities can be found in Appendix A.

Savignon (1997) presents two distinct types of role-plays: unscripted and scripted role-playing. Unscripted role-playing and improvisation are considered the same by 
Savignon. In this activity, the teacher defines a situation and has groups of two or more students interact. A discussion follows the interaction. Savignon discusses some suggestions that could be used in the implementation of the activity. They include audience participation, role-playing characters in a novel, and using hand puppets in place of actors. Scripted role-plays are quite different from unscripted role-plays since they require the use of prepared scripts. These scripts, which range from poetry reading to three-act plays, provide learners with the opportunity to interpret and focus on the meaning or intent of the dialogue. Savignon suggests that scripted role-plays “... may be developed into a full stage production with costumes, props, and lights" (p. 191).

Di Pietro (1990) acknowledges the great importance of role enactment in the L2 acquisition process and discusses features that distinguish between the kinds of roles portrayed in the language classrooms through role-playing. He characterizes roles as being goal-oriented, multidimensional, and paired. The first feature suggested by the author is related to the agenda inherent to the roles. The agenda, which may range from a quickly executed activity to a more complex one, sets a goal to be achieved as well as the means to achieve it. The second feature, multidimensional, is not always present in roleplays. A role is multidimensional when the learner has the freedom to choose how it should be enacted. Although the agenda has been set, the way the situation should be dealt with is not. The last characteristic, paired, refers to “...sets of roles with matched or mismatched agendas" (p. 5). An example of roles with matched agendas would be a salesclerk and a customer, whereas a salesclerk and a window shopper would have a mismatched agenda. Unpaired roles also occur; however, they will lead to monologues. 


\section{Role-play: a Definition}

Several other activities involving enactment have also made their way into language classrooms. They are sometimes considered types of role-plays and are always confused with it. Although their definitions overlap to some extent, these activities also have some distinct characteristics. These activities include: simulation, improvisation, socio-drama, and scenarios.

Simulations are defined by Jones (1982) as “....reality of function in a simulated and structured environment" (p. 5). They are classroom events that are shaped by participants. In these events, learners “...have roles, functions, duties and responsibilities - as ecologists, king, manager, explorer, reporter, survivor, administrator - within a structured situation involving problem solving and decision making” (p. 2). The author claims that all simulations contain three essential elements: reality of function, simulated environment, and a structure built around some problem or problems. Just like Jones' notion of simulation, Savignon's (1997) idea of simulation involves decision making. She holds that simulations are simplifications of real-world situations. For Paulston and Bruder (1976), a simulation activity is one in which the student is assigned the role of playing himself.

Littlewood (1981) defines improvisation as “...the form of role-playing in which learners can be most creative" (p. 62). Improvisations take place when learners are asked to project themselves into a simple everyday situation or a more complex situation, and to interpret and exploit it any way they want. The instructor has little control over the interaction. They may even simply determine the situation, and let learners perform impromptu. Savignon (1997) describes improvisation as an unscripted role-playing, whose features have previously been mentioned. 
Socio-drama is another classroom technique that resembles role-playing. In fact, Scarcella (1978) defines socio-drama as “.... a type of role-play involving a series of student enactments of solutions to a social problem" (p. 42). The activity differs from regular role-plays in some important ways. First, socio-dramas involve a series of specific steps, which may include audience preparation, discussions, and reenactment. Second, socio-dramas are student-oriented since students may select their roles, and they always decide their course of action during the enactment. Students have to relate to the role somehow in order to enact it. Finally, socio-dramas last longer than role-plays because they involve many enactments.

The open-ended scenario, suggested by Di Pietro $(1982,1983)$, is a pedagogical device that has a lot to do with traditional role-plays. Nevertheless, the differences between scenarios and role-plays are much more significant than their similarities. In scenarios, roles are used to simplify situational details; however, the course of the action is completely open to the performer (Di Pietro, 1987). The activity was designed to expand role-play activities in order to force learners to make decisions and change the course of the action as new information is added. During the interaction, new developments and/or new information are introduced and learners change their communication as they work to find the most appropriate solution to a social problem. This open-ended feature and the dramatic tension developed by the differing positions of the participants that are present in scenarios (but not often in role-plays) are the main differences between the two activities.

These types of role-enactment overlap, and their definitions may be difficult to understand. Therefore, for the purpose of the current study, role-play activities are defined according to Abraham (1996): "Role-play is a task in which a person portrays 
$\mathrm{him} / \mathrm{herself}$, or assumes a real or fictitious identity for purposes of presenting an event as interpreted by the (new) character" (p. 11).

\section{Strengths and Drawbacks}

Since the introduction of CLT, role-plays have been successfully established as a language classroom activity. The interest in the technique by those who work with second language teaching can be attributed to numerous reasons. Perhaps its most important feature is that "role-playing allows learners to explore situations that would otherwise never come up in the classroom" (Savignon, 1997, p. 187). In other words, role-plays allow for the classroom setting to be expanded, and its limitations to be overcome, at least to a certain extent (Guntermann, 1980; Littlewood, 1981; Purcell, 1993). Role-plays are especially beneficial to those learners that are tired of spending “...their class time talking about grammar, themselves, or the opinions of their classmates" (Savignon, 1997, p. 187). Instead, role-plays encourage the production of utterances that are unpredictable and generated by context (Ladouse, 1982). They encourage freer use of language (Rodriguez \& White, 1982). In addition, bringing the outside world, that is, real-life situations, into the classroom will help students keep sight of the real functions of the language they are being taught (Di Pietro, 1983). Littlewood (1981) adds that, outside the classroom, learners will have to deal with different patterns of interaction, a variety of communicative needs, and they will be involved in different kinds of social relationships. Therefore, role-plays are necessary in language classrooms to help students learn to cope with these functional and social needs. According to Taylor and Wolfson (1978), roleplays represent "...the best approach available to simulate reality in a classroom" (p. 39). Using the target language and representing people other than themselves are also considered benefits of role-play activities. Di Pietro (1990) argues that through role- 
playing, the target language becomes a tool learners have to use to interact and experiment with roles that they play or would like to play in real life. Ladouse (1982) suggests that during role-plays learners are able to try out language without risk. Some authors attribute this to the fact that learners are not playing themselves. Purcell (1993) holds that performers will often react differently to a situation if they are representing someone else. Harmer (1991) posits that while role-playing, “...students do not have to take responsibility for their own actions and words - in other words, it's the character they are playing who speaks, not themselves" (p. 133). This explains why students are likely to lose their inhibition and shyness through role-playing (Purcell, 1993).

During role-plays, learners are provided with the opportunity to interact in a variety of situations and settings using different registers and functions. They have to try to communicate in ways that are not only functionally effective, but also that conform to the social rules governing the role-play being acted out (Littlewood, 1981). Therefore, role-plays are believed to promote cultural understanding to ESL learners (Scarcella \& Oxford, 1992). That is how they get to know the behaviors, habits, and values of the speakers of the target language. Scarcella and Oxford find role-plays a good technique to develop cultural knowledge because they “...provide a relatively safe, protected situation in which students can make cultural and language mistakes without feeling too threatened" (p. 189). Besides, the authors maintain that, by debriefing after role-play enactments, students can analyze miscommunication and the reasons why it occurred.

In spite of all the advantages attributed to the use of role-plays in language classrooms, there are also drawbacks that can limit the effectiveness of the activity. Ducroquet (1991) states that "role-play first of all is not and cannot be a realistic situation" (p. 49). Taylor (1982) also addresses the same issue. He claims that because 
students know the situations are not real, they do not produce the language that teachers expect. In his example, students were acting out a role-play in which they were looking for an apartment. Even though the teacher had presented the related vocabulary, common idioms, and useful expressions, the volunteers failed to ask questions about utilities, parking, the lease, and the number of bedrooms. They had to be prompted by the teacher. Taylor believes this would not happen if these students were really renting an apartment. As Ducroquet (1991) points out, pretending that you are in a situation that you are not is not the kind of thing everyone finds easy to do.

The outcome of an interaction can be even more disappointing when the situations and roles are not part of the students' needs and experiences. Piper (1984) maintains that “...fictitious roles and situations, particularly if too far removed from the students' experience, contribute to the failure of these activities" (p. 29). Piper and Piper (1983) are of the opinion that in order for learners to practice the language they need, they should be assigned roles they are likely to assume in everyday life. Nevertheless, in many roleplays, each real-life situation requires a student to play a role that he or she is not likely to assume in real life. For instance, in a situation in which a learner goes to the post office to buy stamps, somebody has to be the postal clerk (Al-Arish, 1994). It does not seem to be a problem to Littlewood (1981), who claims that the language that learners practice when they act out less relevant roles is still important. However, Al-Arish (1994) finds that it is hard for students to share Littlewood's point of view. In Al-Arish's opinion, learners tend to resist assuming these types of roles.

The artificiality in role-plays goes beyond the lack of reality of goals and situations presented. Since only a few students have the chance to talk at a time, the others are left to watch, creating a passive audience. According to Al-Arish (1994), this 
audience indicates the unnatural communicative process role-plays involve. He states that "students know that in almost all communicative situations in which they will engage in the real world, there will not be an audience looking over their shoulders" (p. 344). Although Paulston and Bruder (1976) consider the audience to be an essential component of role-plays, Al-Arish (1994) finds it to be an inhibitor of interaction. In addition, Horwitz (1985) points out that the audience will easily lose interest in the role-play if a student performing lacks ideas, or if a student has limited acting skills. This takes us back to another drawback of role-play activities: role-plays favor the actors or more extroverted learners, leaving out the ones that are shy or reserved (Smith, 1986; Ducroquet, 1991).

In summary, even though role-plays pose some unique features to promote the development of communicative competence, the activity presents drawbacks that may jeopardize its success. On the one hand, role-plays allow students to go beyond the classroom limitations and interact to satisfy different functional and social needs. Besides, through role-plays learners are able to use the target language in a nonthreatening situation either because it is just a rehearsal of real-life situations or because they are not playing themselves. In addition, role-plays promote cultural understanding; learners are introduced to the behaviors, habits, and values of the target language speakers. On the other hand, the lack of reality inherent to the activity may prevent students from acting as they would in real life. Moreover, the roles assigned to the students are not always what they are likely to assume in real-life situations. Finally, the issue of the audience also poses a problem to the success of the activity. It inhibits interaction and favors the more extroverted students. Although role-playing has been part of CLT classrooms, its success is not always guaranteed. 


\section{Studies on Role-play Activities}

Since role-playing was established as a successful communicative activity, much has been written about it. Although much of what has been said reflects opinions based on classroom experiences that teachers and researchers have gone through, some research projects have been conducted on the subject. These studies investigate the effectiveness of the use of such activities in the classroom, as well as the reasons why they promote communicative competence. Some of these studies and their findings are described below.

Stern (1980) investigated drama in the L2 classroom from a psycholinguistic perspective. Her starting point was the assumption that L2 learners can improve their communicative competence by taking part in dramatic activities. The researcher's interest was to determine psychological factors that can explain why dramatic activities tend to improve the oral competence of L2 learners. Her first step was to investigate a variety of areas in which drama is used as a means of achieving personal goals, and to establish which psychological factors facilitate communication and trigger the desired behavior in the individuals. After that, her investigation turned to ESL classrooms.

The participants in the Stern study were three ESL teachers and 24 nonnative speakers of English. They belonged to three different classes, but they had all recently performed scenes from plays and had had improvisations in their classes. Dramatizing scenes from plays did not involve memorization. The students were told to look at the lines and say them expressing meaning and feelings. Improvisations consisted of interviews of the characters and improvisations based on the scenes. Students were interviewed as if they still were the characters from the scene. Then, the teacher would introduce a situation similar to the scene but adding a twist in character or plot. Students 
were given five minutes, and then they had to perform. In one of the classes the improvisation was based not on the scene but on a role-play game. Students were presented with a situation, and they had to improvise in front of the class.

The participants were asked to answer questionnaires that had both student and teacher components. The student questionnaire “...was designed to elicit their subjective responses to the psychological aspects of drama being investigated" (pp. 88-89). The teacher questionnaire was open-ended and had no reference to the psychological factors being investigated. The review of the related literature as well as the teacher and student questionnaires provided support to what the researcher had hypothesized. Therefore, she concluded that "drama positively affects L2 learning by encouraging the operation of certain psychological factors which facilitate oral communication, i.e., heightened selfesteem, motivation, and spontaneity; increased capacity for empathy; lowered sensitivity to rejection" (p. 95).

Schmidt's (1985) research project intended to define the characteristics of a successful role-play. The researcher developed a role-play model made up of three parts: the pre-enactment, the enactment, and the post-enactment. Each part included a set of procedures to guide instructors throughout the presentation and implementation of the activities. Based on this model, Schmidt created eight role-play activities which included situations such as a job interview, and an emergency phone call, among others. The next step was to assess these eight role-plays that had been designed.

In order to evaluate her role-play model and also the eight activities she developed, the researcher had two different groups of students perform them. Each roleplay was acted out twice: one by learners in junior college classes and the other by learners in adult school. The participants had approximately the same degree of language 
proficiency; however, the junior college students had better command of spoken language. The students were presented with and guided through the role-plays in the same fashion, following her model. After the post-enactment of each role-play, students and teachers answered a questionnaire evaluating the success of that particular role-play. The items on the questionnaire focused on the topics of the role-play, the "actors" and their performances, the preparation, and the teachers' talking time and helpfulness during the activity. Since the learners' answers to the questionnaire were overwhelmingly positive, the researcher concluded that the topics covered by the tasks and the basic format of these eight role-plays specifically designed for the study were valid. The results showed that there was an overall approval of the role-plays. The activities received the same kind of support from both groups, suggesting that the role-plays were compatible to either learning situation.

In the case study conducted by Raz (1986), the focus was on the possible effects of role-playing on communicative competence, motivation, and under-achieving foreign language learners. The study was carried out in six Israeli schools, and it included 200 intermediate students of EFL. The treatment received by the experimental group consisted of one role-play activity per week over a fourteen-week period of time. The teachers in charge of the experimental group classes were randomly chosen, and then trained in special workshops. The influence of role-play techniques on communicative competence was determined by communicative competence tests administered before and after the experiment. Attitude questionnaires were used to establish the effect of roleplays on motivation. The results showed that the experimental group scored significantly higher than the control group in all sections of the communicative competence tests. In addition, the questionnaires showed that role-plays have a “...beneficial effect on 
intrinsic motivation, on self-concept and the expectations of success of the learner, and on their anxiety when speaking the language" (p. 226).

The study carried out by Hull (1986) analyzed role-play activities based on two of the four dimensions of communicative competence: sociolinguistic and strategic competence. The researcher looked for traces of sociolinguistic competence in learners' speech by analyzing appropriateness in expressions of opinion. The category of repair was examined for evidence of strategic competence because it involves correction of linguistic forms and negotiation of meaning. The data were collected through observation from a total of three conversation classes at two English programs in Hawaii. The participants consisted of 34 low-intermediate and intermediate international students; among them, there were 24 Japanese speakers. The role-plays used were part of a fifteenunit set of role-play activities developed for L2 learners. Each unit had two role-plays that required two fifty-minute classes to be carried out. The role-plays were made up of three phases. Pairs were audio recorded during the third phase, while the class was practicing.

The data showed little evidence of sociolinguistic competence. Only a few utterances were clearly appropriate, while the vast majority were inappropriate. These utterances were comprehensible and not rude, but it was obvious they had been produced by nonnative speakers. Hull (1986) noticed that the sociolinguistic inappropriateness of these utterances may have been caused by the learners' linguistic limitations. He also observed the inadequacy in the selection of lexical items and the use of the modal must. However, learners demonstrated a considerable amount of strategic competence. The researcher found extensive evidence of self-correction and successful negotiation of 
meaning. There was no evidence of embarrassment and breakdowns in communication. Instead, most interactions led to successful outcomes.

The purpose of Su's (1990) study was to investigate and evaluate the effectiveness of role-play activities in learning EFL in Taiwan. The subjects in this study were 40 Chinese freshman students who had had at least six years of English instruction. Their language proficiency was considered intermediate, and they had difficulty interacting in spoken English. These students would teach English in secondary schools after graduating from college. While the experimental group had role-plays as the main teaching activity, the control group had a combination of grammar translation and playacting. The latter is a technique that consisted of memorizing and performing dialogues. The subjects' language proficiency was assessed by an oral test and by the Michigan Test of English Language Proficiency. These tests were administered before and after the experimental period. In addition, two questionnaires were used to assess the effects of role-plays on their affective development as well as on their language learning behavior.

The analysis of the data collected allowed the researcher to draw several conclusions about the effects of role-plays on the EFL students. First, participation in role-play activities promoted progress in language proficiency, especially oral ability. The researcher noted that there was no difference between the experimental and control groups in the development of vocabulary, grammar skills, and reading and listening comprehension. Second, role-plays seemed to lower inhibition, nervousness, and embarrassment levels. Besides, the activity led to improvement of language learning behaviors, such as asking the instructor for explanations, and answering questions in English. Also, it was apparent that the participation in role-plays made students more motivated, more involved in learning, and more active. 
The studies described in this chapter provide valuable empirical information about the use and effectiveness of role-play activities. First, activities that involve drama seem to trigger certain psychological factors that facilitate oral communication and affect second language learning positively. It has also been pointed out that role-plays increase motivation, but at the same time produce anxiety and increase embarrassment levels. Furthermore, the activity promotes progress in language proficiency, especially in oral ability, development of strategic competence, as well as improvement of language learning behavior. The research also showed that there is no evidence that role-plays promote the acquisition of sociolinguistic competence. In addition, researchers did not find evidence in these studies that role-plays lead to development of vocabulary, grammar skills, reading and listening comprehension. These results provide instructors and other researchers with tools to better understand the teaching and learning processes.

In spite of the extensive literature on role-play, it seems that not enough attention has been given to the learners' perspectives. The studies that have addressed this issue have done it superficially, usually as a secondary part of the study. Stern (1980) made an effort to elicit students' subjective responses to the psychological aspects of drama being investigated in her study. The student questionnaire she designed addressed issues such as the usefulness of participating in drama related activities, students' feelings about themselves during and after performance, and the students' interest in participating in dramatic activities. However, the student and the teacher questionnaire were the researcher's only sources of data. She did not observe classes in which the dramatic activities took place nor did she interview the students individually to have a thorough understanding of the students' perspectives. The student questionnaire used by Schmidt (1985) was designed to evaluate the performance and accuracy of the learners, the 
preparation time, and the teacher's participation in the eight role-plays she developed for the study specifically. Su (1990) investigated the effects of role-plays on learners' affective development and language learning behavior. One of the questionnaires she used included, among others, questions concerning the students' reactions to role-plays. However, Su's study differs from the present study because it was conducted in Taiwan, which is an EFL environment, and the participants shared a common first language.

Role-play activities are still part of many current textbooks used in both ESL and EFL classrooms. Although teachers are interested in a variety of methodological approaches and new teaching strategies to promote and facilitate learning, students are not necessarily as accepting of such changes. They may be reluctant to accept "new" techniques proposed by teachers. Studies have shown that teachers and students perceive classroom tasks differently (Block, 1994; Nunan, 1986; Kamaravadevely, 1991). Since these mismatches between teachers' and students' perceptions of classroom tasks can influence the effectiveness of teaching strategies, it is important for the learners' point of view to be considered when planning instruction. Therefore, the purpose of the current study is to investigate the learners' perceptions of role-play activities. 


\section{Chapter 3}

Design and Methodology

Role-play activities became the focus of this research project for three reasons. First, there have been a number of claims and counterclaims about the use and effectiveness of these activities in the language classroom (Paulston \& Bruder, 1976; Maley, 1980; Littlewood 1981; Rivers, 1981; Taylor, 1982; Piper \& Piper, 1983; Ducroquet, 1991; Scarcella \& Oxford 1992, Al-Arish, 1994). However, the students' perspective has not been dealt with in depth. Much of what is known about the way students perceive role-play is based on teachers' and researchers' intuitions. Second, AlArish (1994) argues that role-playing is losing its role in CLT classrooms. His claim is supported by the fact that "there have been fewer articles on role-playing in the field's scholarly and popular journals, especially when compared with the plethora of articles in the 1970s and early 1980s" (p. 338). Although Al-Arish's claim may be accurate, the use of role-plays is still pervasive in language textbooks. Sound ideas by Fragiadakis and Maurer (1995), All clear! by Fragiadakis (1997), New interchange by Richards, Hull, and Proctor (1997), and Talk it through by Kozyrev \& Baker (2001) are a few of the textbooks that feature role-play activities and are currently used in EFL and ESL classrooms. Consequently, language learners are still being exposed to role-play activities. Finally, the researcher is interested in learning if ESL students identify roleplaying as a tool for facilitating "real-world" interaction, which is the main purpose of this particular instructional activity. 


\section{Research Questions}

The present study focuses on students' perceptions and judgments of role-play activities. This research project seeks answers to the following research questions:

1) How do ESL learners perceive the use of role-play tasks in the classroom?

2) In what ways do ESL learners believe that role-plays facilitate interaction outside the classroom?

\section{Participants}

The participants in this study were nine students enrolled in an intensive English program at a State University in North Central Appalachia. The group consisted of three Arabic speakers, four Spanish speakers, and two Japanese speakers. There were five male students and four female students, and their age range was between 18 and 32. They were all low-advanced students in a communication skills class. The proficiency level of the participants was assessed by the institution at the beginning of the term. In order to be placed at the appropriate level of the program, the students took two tests: the institutional Test of English as a Foreign Language (TOEFL) and the Michigan Placement Test. As a further check, the communication skills teacher gave them an oral test during the first week of classes. All the participants were placed at level 3A, which requires TOEFL scores ranging from 410-449, and Michigan Placement scores of 55-64. However, some of the participants had higher TOEFL scores. Three Chinese speakers joined the group in the course of the investigation. Although they signed the consent forms allowing the researcher to tape-record them interacting with the participants during role-play tasks, they did not take part in the study. The instructor in charge of the group was also a participant. A more detailed description of the participants is given in chapter 4 . 
Table 1 presents information regarding the participants' gender, age, mother tongue, and TOEFL score. This information was taken from the questionnaire. 
Table 1

Students' Demographics

\begin{tabular}{lcccc}
\hline Participants & Gender & Age & Mother tongue & TOEFL score \\
\hline Diana & Female & $18-24$ & Spanish & 497 \\
Camila & Female & $18-24$ & Spanish & 427 \\
Luisa & Female & $18-24$ & Spanish & 473 \\
Andres & Male & $18-24$ & Spanish & 503 \\
Takashi & Male & $18-24$ & Japanese & 402 \\
Yuki & Female & $18-24$ & Japanese & 470 \\
Nasser & Male & $25-32$ & Arabic & 430 \\
Ahmed & Male & $18-24$ & Arabic & 410 \\
Fahad & Male & $18-24$ & Arabic & 410 \\
\hline
\end{tabular}




\section{Setting}

The intensive English program has a skill- and content-based curriculum. The students enrolled in the program are presented with a variety of courses. The core courses include Reading/Vocabulary, Writing, Grammar, and Communication Skills. They also take elective courses such as Business English, TOEFL Preparation, American Culture, and English Through the Arts. Although the students make use of the four-skill areas (reading, speaking, writing, and listening) in all the classes, each course focuses on specific areas for skill development and/or content knowledge.

The focus of the Communication Skills course is on improving the learners' ability to speak and understand spoken English. In the low-advanced communication skills class, the students work on developing both listening and speaking skills associated with the idiomatic language found in formal and informal conversations. They also develop skills that will encourage them to participate effectively and meaningfully in their academic classes. The classes that were observed took place in one of the buildings on the university campus. The classroom was large, and it had two big windows that allowed a lot of light to come in to the room. There were two blackboards on one of the walls. There was also a television and a video cassette recorder sitting on a cart in one corner of the room. The 15 desks were always arranged in a semi-circle facing the teacher to facilitate communication.

\section{A Qualitative Research Design}

Since the focus of the study lies on students' perceptions of role-play activities, a qualitative research design seemed to be more appropriate than a quantitative one. In order to find answers to the research questions proposed, the researcher must study learners in their natural setting and interpret their actions. Therefore, the researcher has to 
rely on a research method that is "...pragmatic, interpretive, and grounded in the lived experiences of people" (Marshall \& Rossman, 1999, p. 2). Qualitative methods are preferable for providing researchers with tools to better understand the participants' thoughts, feelings, and experiences.

Three data-gathering methods were used in this research: observations, questionnaires, and interviews. The objective was to collect data from different sources so that the findings could be triangulated. Triangulation is defined by Marshall and Rossman as “ ... the act of bringing more than one source of data to bear on a single point" (p. 194). These data collection techniques are explained below, followed by a detailed account of the procedures.

\section{Observation}

The observations were a fundamental and important source of data. Each observation consisted of “....systematic noting and recording of events, behaviors, and artifacts in the social setting chosen for the study" (Marshall \& Rossman, 1999, p.107). Classes were observed over a seven-week period of time, during the spring term from March 19 to May 2. Although the focus of this research project was role-play activities, the researcher documented events and behaviors that occurred in the setting during all the classes observed. Through observation, the researcher was able to record the participants' actions and interactions in the classroom, as well as their reactions to role-play tasks. Besides taking notes of events and behaviors in the classroom, the researcher taperecorded the role-plays that were acted out by the students in front of the classroom. This was an essential source of data since an underlying assumption of qualitative research is that values are expressed through behavior (Marshall \& Rossman, 1999). 


\section{Questionnaire}

The questionnaire included twenty-four questions which included both structured response and open-ended questions (Appendix B). The purpose of the questionnaire was to elicit information about the learners' prior and current language-learning experiences, and learning strategies. The questionnaire also provided personal data such as age, educational level, and motivation for studying English. These questions were selected to enable the researcher to learn about the participants' backgrounds as well as their perceptions of language learning. The researcher also intended to get a glimpse of what they had experienced earlier which could have shaped their language learning perceptions, behaviors, and attitudes.

\section{Interview}

Both the learners who took part in the study and the instructor in control of the group were interviewed. The student interview consisted of thirteen open-ended questions (Appendix C). These questions focused on the participants' perceptions of roleplay activities. The participants were asked questions about their experience of acting in the classroom and how they could benefit from it. The researcher's aim was to understand their experience and what they made of it. In order to obtain more accurate responses and to make sure the participants associated the interview questions with the correct classroom activity, the participants were asked to listen to themselves acting out a role-play that had been previously taped.

The teacher interview encompassed nine open-ended questions (Appendix D). The instructor was asked questions regarding her language teaching beliefs, her own as well as her students' perceptions of role-play activities, and her opinion about each individual learner. 


\section{Procedures}

The research project was carried out in a low-advanced communication skills class that met for one hour and fifteen minutes twice a week (Tuesdays and Thursdays). The students were approached and invited to take part in the project in their classroom. The researcher explained to the students that she was interested in learning their opinions about certain classroom activities. The students were not told role-plays were being investigated. Then, the researcher explained the whole procedure and the students' role in the process. Next, the students were allowed some time to ask questions. After all questions had been answered, the students were asked to sign a consent form which contained information about the research and the researcher. All the students agreed to take part in the study. On the next day, the participants received a copy of the consent form they had previously signed. Their participation was voluntary; that is, they did not receive any kind of payment for being in the study. They were also told that their grades would not be affected by their participation in the study.

As stated above, the purpose of this study was to gather data about the learners' view of role-play activities as they occur naturally in language classrooms. Therefore, no activities were designed by the researcher. It was up to the instructor to make use or not of the activities being investigated. All the role-plays in which the instructor had students act out for the class were tape-recorded.

After the researcher had observed the participants develop a role-play task in class, the questionnaire was administered. This was done to ensure that the students knew what role-playing was, even though the instructor guaranteed they had had role-plays before. The participants met the researcher outside of class time to answer the questionnaire. Not all the participants answered the questionnaire at the same time. The 
first group to answer it, six students, took approximately 15 minutes to complete the task. The other three participants got together two days later to answer the questionnaire, which took them 15 minutes as well.

The researcher began the interviews during the sixth week of the research study. All of the participants were interviewed in the same week. These one-to-one interviews took place in the researcher's office, and lasted around 15 to 25 minutes each. The interviews were conducted in English, and they were tape-recorded. Due to the participants' language proficiency, the researcher read all the interview questions to the participants, and explained the questions they did not understand before the interview started. This approach was an attempt to make the students more comfortable and to avoid misunderstandings. After that, the participants were asked to listen to themselves acting out a role-play that had been previously recorded in their communications skills class. Finally, the interview itself took place. Each participant was interviewed once. The instructor was interviewed in her office after the eighth week. This interview was also tape-recorded and lasted about 20 minutes.

Over a period of seven weeks, the participants acted out six role-play activities. Three of these role-plays were activities proposed by the textbook Talk it through (Kozyrev \& Baker, 1999), which is the assigned text in the communication skills class. The other three role-plays were either designed by the instructor or taken from supplementary materials in order to provide extra practice with the structures presented in the textbook. Five of the role-plays performed in class were tape-recorded as students acted in front of their classmates. Only one of the six activities was not taped because the instructor did not single out pairs or groups to perform for the class. Instead, all of the 
students acted out their situations simultaneously. All the role-plays and the interviews were transcribed by the researcher herself.

The role-plays used in the class during the observation had the same format. In these activities, the learners were presented with a situation, and they were supposed to achieve the specific goal of the task through communication. The students were not told what they had to do to achieve the goal. The learners had plenty of control over their interaction. According to Littlewood's (1981) activity continuum, which was discussed in the previous chapter, these activities are classified as role-plays controlled through situations and goals. For examples of these role-plays, see Appendix E.

In the following chapter, the findings encountered in the different sources used for data collection are presented. These findings are organized into categories that were identified during the analysis of the questionnaires, the observations, and the interviews. 


\section{Chapter 4}

\section{Findings}

The purpose of this chapter is to report on the findings obtained regarding the students' perceptions of role-play activities. The analysis of the data collected through observations, a questionnaire, and interviews revealed three persistent categories: the benefits of role-plays; the limitations of role-plays; and the feelings and reactions to roleplays. Therefore, I have decided to organize and present the findings of this study by grouping the information in the categories that emerged from the analysis of the data. This organizational approach enabled me to answer the research questions posed before: (1) How do ESL learners perceive the use of role-play tasks in the classroom? and (2) In what ways do ESL learners believe role-plays facilitate interaction outside the classroom?

For a better understanding of the findings a detailed description of the participants is provided next. All of the data that follow were taken from the questionnaires, observations, and both student and teacher interviews. This information is extremely important because of the qualitative nature of the current research. As the participants' personalities and backgrounds are described, their opinions and reactions to role-play activities can be interpreted more accurately. The names of all of the participants have been changed for the purpose of confidentiality. All the quotes used in this chapter consist of what the students said originally in the interviews, and errors have not been corrected.

\section{The Participants: a Closer Look}

In this section, each participant is described individually. The descriptions include personal information such as educational level and motivation for studying English. In 
addition, they contain personality traits that might influence the way these students perceive role-play activities.

Diana is a Venezuelan lawyer who dreams about going to Australia. She had been living in the United States for the past three months, and she planned to learn English so that she could go to an American university, read publications in English, and ultimately get a better job. She is very talkative and opinionated, even though she considers herself a little shy. She could get really agitated in class, and oftentimes caused some uncomfortable situations. Diana was very active and loud in class, and she was always willing to contribute to the class.

Luisa is another student from Venezuela. This high school graduate had arrived in the United States eight months before the study began. She planned to learn the English language for professional reasons. Although Luisa is clearly a shy person, she was anxious to take part in class activities. She spoke softly, and sometimes it was even hard to hear her.

Camila is a young industrial engineer who has plans to go to graduate school in an American university. This well-spoken Venezuelan was very eager to talk and participate. Her willingness to write on the board became the joke of the class. Every time she had the chance, she would walk towards the blackboard as if she were a model. She describes herself as a happy and talkative person who laughs a lot. She volunteers for every activity, and she makes sure she answers all the questions asked. She believes that interacting with people is the best way for her to learn English.

After graduating from high school, Andres moved from Colombia to the United States. His goal was to learn English before he started his undergraduate studies in America. Andres was not part of the group originally. He joined the class mid-term. Most 
of the time, he was quiet and reserved. He usually paid attention to everything going on in class. However, it was not unusual to notice him gazing at the ceiling or at the clock on the wall. Unlike the other South Americans, Andres participated only when he was called on. On some rare occasions, he would say something out of the blue and even be funny.

Takashi is a Japanese high school graduate who had been studying English for more than six years. He had already studied in the program before. However, he had had to go back to Japan where he worked in a variety of jobs: sales person, cook, and waiter. According to the instructor, coming back to the same program after a year gave him a unique perspective. She believed he had time to think about all he should have done here, and as a result, he came back as a student who went above and beyond the call of duty. Since Takashi had to work, he was always late to class. However, he never failed to greet the teacher and his classmates as he walked in shyly. He did not talk much, but he always found the right time to express his opinions and make precise comments. His main objective was to enter an American university.

Going to college in the U.S. was also the reason why Yuki spent seven years studying English in Japan. When she joined the communication skills class, one month before the study began, she was amazed by her classmates' fluency. She is extremely reserved and soft-spoken. She thought she was too shy, but she wanted to communicate with a lot of people. She never volunteered in class, and even when she was put on the spot, she was reluctant to talk. The instructor always complimented her on the stylish shoes she used to wear. Yuki always responded to the compliments with a smile and a timid bow.

Nasser was the oldest in the group, and he seemed intensely interested in learning English. Nasser is a Saudi college instructor who came to America to get his second 
Master's degree. In class, Nasser was a unique student. Because he was so eager to learn, he was always willing to participate in all of the activities proposed. As soon as the instructor started asking a question, he would raise his hand and start waving it. He did not give the other students a chance to answer. Nasser is a very respectful and grateful person, even though he could have been perceived as aggressive because of his deep tone of voice and enthusiasm. He was extremely friendly to the other Saudi students and the instructor. However, he did not have the same attitude towards the Latin American women.

The most extroverted student in this class was Ahmed. He is a very talkative student who felt at ease when interacting in English. He is very creative and he always has something to talk about. He enjoys being around people. Although he seemed to talk constantly in class, the instructor did not see it as a problem. Instead, it was sort of a joke in the class, and it helped get students involved. Actually, he was quite respectful of other students' talking time. Ahmed is originally from Saudi Arabia, where he graduated from high school just before coming to the United States. He had never studied English before arriving in America a year before taking part in this study.

Ahmed's brother, Fahad, is also a Saudi high school graduate who planned to get his B.S. in an American university. Before coming to the U.S., Fahad spent some time in England developing his English skills. He defined himself as a lazy student who did not like to do homework. His concern was the TOEFL. Fahad was certainly the most popular student in class. He was fun-loving, outgoing, and very courteous to his female classmates. He was never able to take things very seriously; he is the kind of person who is ready to make a joke and make all of the students laugh. Even though he used Arabic customs and traditions as the topic of his jokes, they were not offensive to anyone, not 
even to the other Saudi students. Because of his fun-loving nature and amiable attitude, Fahad was always surrounded by the other students.

Judy is an American ESL instructor in her mid forties. She has a Master's degree in Teaching English to Speakers of Other Languages (TESOL), and she is working on an Ed. D. in Curriculum and Instruction. She has taught ESL for eight years. She is a charismatic person, who has a great sense of humor. She is one of the most popular teachers in the intensive English program in which she teaches. She is open-minded and understanding of cultural differences, especially because she lived in Brazil for one year as an exchange student when she was 18 years old. She tried to incorporate role-plays into her lessons because she believed that the activity benefited students in several ways. She stated:

They [students] have to think on their feet. They have to think quickly. They have to deal with situations that they may never deal with or that they may not have the opportunity to deal with because they live together with people from their own cultures. That does not give them the experience of really speaking English in day-to-day situations.

The participants in this study come from four different countries: Venezuela, Colombia, Saudi Arabia, and Japan. Since all the participants received English instruction in their native countries, I found it appropriate to learn about activities and methods that these participants had been exposed to prior to their coming to the USA. This information may be valuable for understanding how students perceive role-play activities. Apparently, the focus of language teaching in the EFL environment was on more traditional approaches. The participants identified drills and translation as the most common activities. Unlike the EFL environment, the ESL environment seemed to be more focused 
on communicative approaches of language teaching. Although drills were used, a lot of attention was given to communicative activities such as group discussions and role-plays. Tables 2 and 3 show the activities the participants experienced in their English classes both in their native countries (an EFL environment) and in the United States (an ESL environment). 
Table 2

Activities Students Experienced in an EFL Environment

\begin{tabular}{lccccc}
\hline Participants & Translation & Drills & $\begin{array}{c}\text { Act out } \\
\text { commands }\end{array}$ & $\begin{array}{c}\text { Group } \\
\text { discussion }\end{array}$ & Role-plays \\
\hline Diana & $\mathrm{X}$ & $\mathrm{X}$ & & $\mathrm{X}$ & $\mathrm{X}$ \\
Camila & $\mathrm{X}$ & $\mathrm{X}$ & $\mathrm{X}$ & $\mathrm{X}$ \\
Luisa & $\mathrm{X}$ & $\mathrm{X}$ & & \\
Andres & $\mathrm{X}$ & $\mathrm{X}$ & & & \\
Nasser & & $\mathrm{X}$ & $\mathrm{X}$ & \\
Ahmed & & $\mathrm{X}$ & $\mathrm{X}$ & \\
Fahad & & $\mathrm{X}$ & & \\
Takashi & $\mathrm{X}$ & $\mathrm{X}$ & & \\
Yuki & & & & \\
\hline
\end{tabular}


Table 3

Activities Students Experienced in an ESL Environment

\begin{tabular}{lccccc}
\hline Participants & Translation & Drills & $\begin{array}{c}\text { Act out } \\
\text { commands }\end{array}$ & $\begin{array}{c}\text { Group } \\
\text { discussion }\end{array}$ & Role-plays \\
\hline Diana & $\mathrm{X}$ & $\mathrm{X}$ & $\mathrm{X}$ & $\mathrm{X}$ & $\mathrm{X}$ \\
Camila & $\mathrm{X}$ & $\mathrm{X}$ & $\mathrm{X}$ & $\mathrm{X}$ \\
Luisa & $\mathrm{X}$ & $\mathrm{X}$ & $\mathrm{X}$ & $\mathrm{X}$ \\
Andres & $\mathrm{X}$ & $\mathrm{X}$ & $\mathrm{X}$ & $\mathrm{X}$ \\
Nasser & & $\mathrm{X}$ & $\mathrm{X}$ & $\mathrm{X}$ \\
Ahmed & $\mathrm{X}$ & $\mathrm{X}$ & $\mathrm{X}$ & $\mathrm{X}$ \\
Fahad & $\mathrm{X}$ & $\mathrm{X}$ & $\mathrm{X}$ & $\mathrm{X}$ \\
Takashi & & & $\mathrm{X}$ & $\mathrm{X}$ \\
Yuki & & & $\mathrm{X}$ \\
\hline
\end{tabular}


In addition to prior experience, the individual goal for English language study may have been significant. All of the nine participants expressed a desire to develop their communication skills. They provided several reasons to explain their need for oral skills. Eight participants had a similar point of view; they planned to enter an American university in the near future. Therefore, they wanted to function in the American environment. As Takashi suggested, “It's very important because especially I'm here. I need to talk; I need to speak English.” Fahad pointed out the importance of developing communication skills to function in the target language environment by saying, "I think it's very important. Maybe you can read, and you can write; but you can't speak outside because you're not American people. You have to, at least when you go to a restaurant, you have to order." Unlike the other participants, Camila had professional reasons to improve her oral abilities. She explained, 'I'm an industrial engineer, and if I'm going to my country, it's required to get a job to speak English. I don't need to write a lot. Instead, I need to speak with another person, something like that." The students' reasons for studying English are illustrated in Table 4. 
Table 4

Participants' Reasons for Studying English

\section{Participants Reasons}

\begin{tabular}{|c|c|c|c|c|}
\hline & $\begin{array}{l}\text { Learning about } \\
\text { the culture }\end{array}$ & $\begin{array}{c}\text { Getting a better } \\
\text { job }\end{array}$ & $\begin{array}{c}\text { Going to an } \\
\text { American } \\
\text { university }\end{array}$ & $\begin{array}{c}\text { Reading English } \\
\text { publications }\end{array}$ \\
\hline Diana & & $\mathrm{X}$ & $\mathrm{X}$ & $\mathrm{X}$ \\
\hline Camila & & $X$ & $\mathrm{X}$ & \\
\hline Luisa & & $\mathrm{X}$ & & \\
\hline Andres & & & $\mathrm{X}$ & \\
\hline Nasser & & & $\mathrm{X}$ & \\
\hline Ahmed & & & $X$ & \\
\hline Fahad & & $\mathrm{X}$ & $\mathrm{X}$ & \\
\hline Takashi & & $\mathrm{X}$ & $\mathrm{X}$ & \\
\hline Yuki & & & $\mathrm{X}$ & \\
\hline
\end{tabular}


Although these participants had plenty of reasons to develop communication skills at the time the interviews were conducted, I also found it appropriate to learn about the English skills that they were more likely to use in the future. It seems that the participants believed that listening and speaking were the two skills that they were more likely to use in the future. Reading and writing, on the other hand, were ranked as skills that would probably play a less prominent role in their futures. Table 5 shows how the participants ranked the English skills from the ones they were more likely to use (1) to the ones they were least likely to use in the future (4). 
Table 5

Skills Students Are More Likely to Use in the Future

\begin{tabular}{lcccc}
\hline Participants & Skills & & & \\
\hline & Listening & Speaking & Reading & Writing \\
\hline Diana & 3 & 2 & 4 & 1 \\
Camila & 1 & 3 & 2 & 4 \\
Luisa & 2 & 1 & 4 & 3 \\
Andres & 2 & 1 & 3 & 4 \\
Nasser & 2 & 4 & 1 & 3 \\
Ahmed & 1 & 2 & 3 & 4 \\
Fahad & 4 & 3 & 1 & 1 \\
Takashi & 3 & 2 & 3 & 4 \\
Yuki & 2 & 1 & & \\
\hline
\end{tabular}

(1) = skill they are more likely to use in the future

(4) = skill they are least likely to use in the future 
Next, the three categories that emerged from the analysis of the data are presented. As mentioned before, these categories include the benefits of role-plays, the limitations of role-plays, and the feelings and reactions to role-plays.

\section{Benefits of Role-plays}

In spite of being aware of some of the drawbacks of role-plays, the participants demonstrated a general approval of the activity. All the participants considered the activity to be helpful. Among the variety of reasons provided to explain how role-plays actually helped them, seven patterns emerged. The participants found that role-plays enabled them to (a) improve oral proficiency, (b) get used to speaking, (c) receive teacher feedback, (d) rehearse for real-life situations, (e) acquire new vocabulary, (f) have fun in class, and (g) learn from classmates. A detailed account of each of these patterns is provided below.

\section{Improving oral proficiency.}

Improving and developing speaking skills seemed to be perceived as the most beneficial feature of role-plays. Four students mentioned, sometimes more than once, that by taking part in role-play activities they learned how to speak. Andres stated, "They can help me to express myself and to speak." Ahmed shared the same point of view. He said, "You learn how to speak with another people. If you need something, [you learn] how to ask about something, ask something from another person.”

Yuki also mentioned developing speaking abilities as one of the positive aspects of role-plays. However, her comment differed from the previous ones since she included understanding people as part of what she learned through role-plays. She said, "I learn speaking and understanding. My partner said to me. I understood, so I answered him.” Fahad was another subject that accounted for the fact of having to understand your 
partner to provide an appropriate response. Besides, Fahad added that students have to think on their own, and come up with answers when they do not have much time. He noted:

It's good sometimes; you learn how to speak. I learn how to find answer very fast because sometimes you just start the role-play and my partner ask me speak about something. I have to agree or disagree; or I have to speak with him the subject very fast in front of the class.

Overall, then, the participants felt that their oral skills improved as a result of their participation in role-plays.

Getting used to speaking.

According to the students, another positive aspect of role-plays is getting accustomed affectively to speaking in the target language. Andres observed that roleplays forced him to deal with unpleasant feelings that he experienced whenever he had to speak English. He stated, "I learn that I can't be scared about to speak," and "I can face my fears and go there and speak. I don't care. I have to do that and get better." Nasser and Ahmed believed that through role-playing students become more comfortable and confident with communicating. Nasser mentioned that role-play interactions allowed students to be more spontaneous when talking. As students role-play again and again, they become less shy. He explained that "when I talk with people first time, I think another person maybe he or she feel shy. But the next time, I think that the wall will drop. After that, you can talk anytime and any person.” Ahmed suggests that the audience plays an important role helping students get used to speaking English to other people. He mentioned that "It helps you because you talk in front of all the students, and like outside [the classroom] you talk not with one person. You talk with people. It helps you." 
Although they had different reasons, some participants believed that role-plays were beneficial because learners get used to communicating in English.

\section{Receiving teacher feedback.}

Receiving feedback from the teacher seemed to be another feature of role-play activities that interested students. Being corrected during or after their performances was something that three of the participants considered advantageous. Nasser believed that “...if I say it wrong, the teacher tell me that. I think this important." Luisa agreed with Nasser. She said, "Maybe you are talking or something, maybe you don't say the correct sentence or word, and the teacher corrects the word." Ahmed also made clear that correction was a positive aspect of the activity by saying, "The teachers correct your pronunciation because sometimes it's wrong."

One interesting point to be made at this point is that during class observations, no corrective feedback was provided to any student on their role-play performances. Even though they made mistakes, the instructor did not correct them at any point as she usually did during other oral interactions. She stated, "I believe role-plays should flow naturally." After two of the six different role-play activities performed in class, the instructor asked the students what they had learned from that activity. Few students answered her questions. There was no follow-up after the other four role-plays. Even though correction was not present in the role-plays students had in class, some of them considered it to be a benefit of the activity.

\section{Rehearsing for real-life situations.}

Three of the participants saw role-play activities as a rehearsal for real-life situations. They thought that acting out different situations in class would help them when they had to face the same situations outside the classroom. Diana believed that role- 
play practices prepared her for everyday situations. She explained, "It's like every day you confront different situations, and if you know how to function in some situations, good for you, because you don't feel like a stupid, you know." And then she added, "The role-plays that I did is good because if I have any problems in the future with my clothes, I know how to do it." Takashi seemed to profit from role-plays in the same manner. He said, “...we learned so many situations on role-play, and it helps me. When I have a real situation, if I already did a role-play about, I think I know like fifty percent how I behave, I know how to act." Camila expressed a similar opinion by saying, “... this role-play is like when you are in some moment and you need to say something. They teach us what to say in that situation, how do you act when you are in that situation."

Diana, Andres, and Nasser were the only three participants that found role-plays totally similar to real-life interactions. Four other subjects acknowledged the similarities, but they were aware of the differences too. Andres defended his point of view by saying, “They [role-play situations] are real situations. Maybe some day, you're gonna pass for that." Similarly, Diana explained:

It's just like the real life. There's time you have to deal with this kind of situations. I think it's the same. You always have to talk with the bus driver; you have to talk with the girl or the guy you are having your lunch; you have to discuss for any problem that you might have in a condition, for example.

Nasser just commented that role-plays and real-life situations were similar, but he did not explain how. Therefore, the participants seemed to relate the situations they had practiced in class to the situations they were likely to face in the real world. 


\section{Acquiring new vocabulary.}

The acquisition of new vocabulary was also mentioned as one of the positive aspects of role-play activities. Since the participants dealt with a number of different situations, they were exposed to new vocabulary which they had to use in their performances. Fahad was one of the participants who mentioned that role-plays were helpful because of the vocabulary that they presented. He stated, "I like about role-plays is sometimes you learn new words, the vocabulary from the role-plays." The other participant who shared his point of view was Camila. She also noted that she benefited from role-play by learning new vocabulary. She said, "You can learn vocabulary and some slangs that people use outside."

One clear example of vocabulary acquisition took place during one of the presentations. Diana and Takashi were assigned a situation in which he played a drycleaner while she was a customer complaining about a shirt. After practicing for a while, the pair started presenting the dialogue to the class. After being greeted by the drycleaner, she said, "Hello. I bring my shirt because somebody (long pause) shrunk (looking at the instructor) - is the word?" The instructor nodded, and she continued, "shrunk my shirt." Most of the students were repeating the word to themselves, even though they did not have to act out the same situation. After this day, the word shrunk was used in class again a couple of times. When the students said the word, they emphasized it, as if they were still testing its usage.

Having fun in class.

Three participants suggested they liked the activity because of the fun it provided. Fahad, Camila, and Ahmed considered role-plays to be entertaining. During the presentations, some students tried to come up with funny dialogues or have a weird 
attitude to make their classmates laugh. They succeeded. The audience laughed a lot because of role-play performances. For instance, Fahad once made up a story in which he had traveled with his wife. When he was questioned about being married, he let the class know that not only was he married, but also he was referring to his third wife. The students stated laughing because Fahad was using the fact that Saudi men may have four wives, which in a way irritated the South American women, to be funny. In the interview with the instructor, she commented on the issue. She noted that, "They [students] like to see who had the most outlandish story, who had the most interesting story, who got the most laughs." This attitude enhanced the students' interest in the activity and in the class itself. As Ahmed stated, "It's fun, and it's a little bit fun in the classroom; and you feel good in the class."

\section{Learning from classmates.}

Learning from classmates' performances was one more benefit students seemed to gain from role-plays. Two participants pointed out that they observed their classmates while they were acting out role-plays in order to learn from them. Ahmed commented, "It's [classmate's performances] good because you listen to them and learn." Similarly, Andres stated, "I just watch them and learn." Curiously, in the interview, Andres explained that his learning took place when he tried to correct the mistakes his classmates had made.

The other three participants did not say they learned from their classmates, but like Andres they seemed to be attentive to their classmates mistakes. Camila said, "I just listen to them and see what they do and what they say... if you say a word, and it's not OK, I repeat in a good way, so they can hear what's the good way." Since I never observed the students correcting their peers verbally, I assume that this was a mental 
correction. According to what Gass and Varonis (1989) suggest, nonnative speakers who are confident that the form they are using is correct tend not to accept external incorrect feedback. These learners tend to maintain the form she or he had used originally. It seems that Camila and Andres were able to identify incorrect forms and compare them to forms in their own interlanguages. Ahmed also paid attention to his classmates' mistakes. He explained, "Sometimes they make a mistake, and the teacher corrects these mistakes, and you know the correct answer."

After having presented all the patterns related to the benefits of role-play activities, I find it important to report on what one individual commented. Takashi found role-plays useful because through role-plays he had insights into American culture. He believed that by role-playing different kinds of situations, he was able to understand the new culture and learn how to behave properly. Takashi recognized that he had to adjust to the new culture and that role-plays helped him. His statement explains his point of view:

I like that we can have, everybody, my classmates everybody has a difference thinking, so it's kind of interesting because how they behave. I compare everyone's behavior because I'm in America right now, and I don't know. In Japan and America sometimes difference, so I want to learn how they do action. In summary, the analysis of the data showed that the students identified seven positive aspects of role-play activities. These aspects include (a) improving oral proficiency, (b) getting used to speaking, (c) receiving teacher feedback, (d) rehearsing of real-life situations, (e) acquiring new vocabulary, (f) having fun in class, and (g) learning from classmates. Besides these seven major patterns, one student's comment on the development of cultural understanding through role-plays was also part of this category that dealt with the benefits of role-play activities. 


\section{Limitations of Role-plays}

The second category to emerge deals with the limitations of role-play activities. The information gathered from the interviews and the observations revealed four problems participants had with role-play activities. The patterns related to this category include a) lack of vocabulary and ideas, b) animosity between students, c) artificiality of performances, and d) artificiality of the task. In this section, the participants' opinions about the negative aspects of role-play activities are presented.

\section{Lack of vocabulary and ideas.}

One of the concerns students had when they did role-plays was not having the necessary vocabulary to express themselves or ideas to keep the conversation going. Andres and Takashi pointed out that one of the problems they had was the lack of vocabulary and ideas, which could prevent them from carrying out the task. Andres said, "I have afraid to don't do it well and maybe get stuck because I start to think, think, think and the words can't come out." Likewise, Takashi expressed his concern, but he also offered a solution, “I don't like when I have no idea about it, when I don't know... when I don't have vocabulary, so it's sometimes difficult to describe; but I can gesture, so I gesture sometimes."

Most of the time, the participants were very resourceful, and they had plenty of ideas. The majority of the role-plays carried out in class were very successful. In spite of the students' opinions that lack of vocabulary or ideas made it difficult to participate in role-plays, there was one problematic performance due to lack of ideas and/or vocabulary. Ahmed, Yuki, and the instructor role-played a situation in which a coupleAhmed and Yuki - interviewed a college graduate interested in working as a maid. Yuki was supposed to disagree with her husband, who wanted to hire the girl, even though she 
could not handle the housework. Ahmed tried to direct the questions to her or lead her into saying something, but Yuki remained silent during most of the discussion. He became uneasy with her poor participation. He looked at the instructor and the other students, who were still interested in the dialogue. Her lack of response caused Ahmed to have an outburst, as you can see in this excerpt of the dialogue:

(1) Ahmed - OK. If you want something, she can teach you.

Instructor - So, do I have the job or not?

Ahmed - Yes, of course you have the job. What do you think my dear wife? (after 30 seconds - Yuki has not answered)

Ahmed - Come on! Kick her out! She drink every day; she smoke... (class laughs)

Instructor - So, do I have it? Ms McDonalds, do I have the job?

Yuki - Do you like cooking?

Instructor - Cooking? If you go to the grocery store and get those little meals... The example above illustrates Andres and Takashi's concern about role-play activities. Lack of ideas and vocabulary can easily put a student on the spot when he/she is performing in front of classmates.

Animosity between students.

According to the students, another limitation of role-play activities is related to the animosity between students. Even though there were no obvious conflicts in class, it was clear that Nasser and the South American women, especially Diana, were not compatible at all. Their relationship was limited to greetings and eventual group-work in class. However, two students were bothered by the attitude of these students during the role-play activities. Ahmed pointed out that he disliked the fact that some people got 
angry during role-plays. They disagreed with each other and, although it was just a roleplay, they took it personally. Diana also observed that her relationship with one of her classmates influenced her opinion about role-plays. She commented:

The only thing I don't like the role-play because I had a problem with, I don't know, if I'm doing with somebody in my classroom, one of my classmates I have problems, I don't like because he is so 'machista," and he tries to impose him, what he think.

It seemed that role-plays provided them with the context within which they could vent their feelings and say what they could not say in real life. For instance, when Diana, Andres, and Nasser performed together, Diana took advantage of the topic of the roleplay to embarrass Nasser and put him down. Diana and Andres played the role of a couple who was interviewing someone to work in their house as a maid. As some of the groups had to interview male applicants, they were advised by the instructor to change the job to better suit the applicant. For example, when Fahad and Luisa interviewed Takashi, they questioned him about his landscaping skills. However, Diana kept asking Nasser to cook, clean the house, and do other chores that are usually attributed to women, especially in Saudi Arabia. The whole role-play is presented in Appendix F. Thus, the animosity between some students was considered a negative aspect not only by those students who did not get along well, but also by the audience.

\section{Artificiality of performances.}

Two participants suggested that performances during role-play activities did not reflect real behavior. Both Camila and Fahad believed that they would act differently if they were really interacting with someone. When Fahad did role-plays, he knew he was performing. Therefore, he took advantage of the acting to entertain his classmates. He 
said, "We didn't make it real because we laugh in the role-plays, and sometimes we make jokes for the person who is standing." Camila also was aware that she was just performing, and she was bothered by the fact that she had to express feelings that were not real. According to Camila, "When you are not in a real situation, you have to do some intonation or some expression that if you are in the real moment, you can't do it. That's why I don't like it."

Artificiality of the task.

Although the participants did not complain about the artificiality of role-play activities, they pointed out that role-plays are quite different from real-life situations. Knowing that the main purpose of the activity is to resemble real-life situations, I have decided to include these comments in the limitations section. Even though three participants claimed that role-plays are similar to real-life situations, the other six participants presented many reasons why they believed the activity differed from real-life situations.

According to Takashi, the person one performed with determined the degree of artificiality of the role-play. In his opinion, the more interactive the partner was, the more similar to real-life situations the interaction was. He maintained that, "It depends on the person. Like Judy [the instructor], it's like real-situation. But if the person doesn't ask many things, it's not real action; but it helps me."

Another difference the participants noticed was that during role-plays, they had to act. Students maintained that they were given roles, and they were supposed to portray them. They had to express anger, have a different posture and attitude; that is, they had to act. Luisa said, "You have to act; put your body in front of all the people and express and talk to them, I mean for them. You have to speak loud." Camila also believed that the 
difference between role-plays and real-life situations was the way they had to behave during the performances. As she stated in a similar comment, Camila added:

It's not real. You use words and slangs and a lot of things you use in a real situation; but is not the same because you don't use the real intonation that you use in a real situation. I'm talking here with you, and I'm mad. I'm not going to start to yell at you like in a role-play, but it's OK.

Fahad agreed with Camila's notion that they used the same words in the two situations. However, he added that the actions were different. He said, "It's the same words, but it's different actions. You don't laugh, you don't look around when you talk [in real-life situations]. It's different."

Yuki and Ahmed pointed out yet another difference. They observed that they always had time to practice before doing role-plays in class, which does not happen in real life. Yuki argued that "Role-play are practice exercise before we are performing in front of my classmates." Likewise, Ahmed added, "In role-plays you practice it before, but outside is different because you talk about something you didn't practice before." Ahmed also raised a very interesting point when he said:

In role-plays, if you make mistakes, everybody will understand. The teacher will correct you and everybody know what you are talk about. But outside you talk with a native speaker. They don't understand if you make mistakes, or you say wrong pronunciation. You have to be careful when you talk with them. Summarizing, four drawbacks emerged from the data. The negative aspects perceived by the students include a) lack of ideas and vocabulary, b) animosity between the students, c) artificiality of the performances, and d) artificiality of the task. Even though the students did not report having problems with the differences between real life 
and role-play situations, the students' comments on this topic were included in this section.

\section{Feelings and Reactions to Role-plays}

The purpose of this category is to present the participants' reports on the way they felt when they had to role-play. In addition, this section focuses on the participants' reactions to role-play activities. First, the participants' account of their feelings while role-playing is presented. Next, the issue of audience is dealt with. Finally, the participants' favorite activities, as well as their opinions about having role-plays in class are described.

\section{How they feel.}

Among the nine participants, Nasser was the only one that reported not having awkward feelings while role-playing. He stated, “It's OK. I don't have any problem about that. I'm comfortable. I think that's OK." In class, he never showed unwillingness to take part in role-plays or any other speaking tasks. Instead, he was always the first to volunteer. While performing, he took his roles seriously, and he wanted to make sure he delivered a good performance. His behavior in class proved that he really felt comfortable during role-plays. However, that was not the case with the other eight participants.

The other students involved in the study related role-plays to a series of unpleasant feelings. Shyness was the most common feeling among the participants. Four of them reported that they felt shy when they were asked to perform in front of their classmates. Camila said, "I feel shy, but I can handle it." Similarly, Yuki commented, "First time, I was too shy, but recently it was interesting for me." Even though the two women felt shy, they did not seem to be bothered by that. Fahad and Takashi also felt shy, but their feelings were related to their performances. Fahad felt shy because his 
performance was not as good as the dialogue he had just practiced with his partner. He said, 'I feel shy, I don’t know. I don’t speak good like when I was sitting and speaking with my partner." Takashi worried about what the other students would think of him. He explained, "I feel a little shy. I sometime think if I say something about role-plays, what do they think about me? I don't need to think about it, but I do sometimes."

Nervousness was what Ahmed and Luisa experienced. At first, Ahmed mentioned, "I don't feel nervous, or I don't feel afraid, or something like this.” However, he later admitted, "I feel a little bit nervous, because, you know, you talk in front all the classmates and the teacher. Sometimes you sweat. Sometimes you move around." In the same way, Luisa said, “Well, I feel like nervous.” Unlike Luisa and Ahmed, Diana felt embarrassed. She commented, “It's embarrassing because I'm shy, you know, I'm a little shy. I don't know. This is funny because sometimes I don't feel; that's OK. But other times, I feel like very embarrassing."

Fear of failure seemed to be what Andres felt before and during role-plays. Andres worried about not succeeding, and that scared him sometimes. He mentioned, "I have afraid I don't do it well. Sometimes I don't care; I just go and do it. But sometimes I feel like 'oh, everybody is scared', and I'm scared, but....” Apparently, Andres believed his classmates were scared too. Andres also commented that he did not feel comfortable with speaking in front of the class. Overall, eight participants reported feeling either shy, nervous, embarrassed, or afraid of not succeeding during role-play activities; one student felt totally comfortable, though.

\section{The audience.}

The participants' feelings were quite different when they were sitting in the audience. The audience seemed to have basically two distinct opinions about their 
classmates' performances. They either found it was important to observe their classmates perform, or they found it was funny. As mentioned before, some students believed that observing their classmates doing role-plays was important because they could learn from them. Other participants, like Nasser, just said that they considered it important. Luisa did not say it was important, but she had a realistic point of view about observing her classmates. She mentioned, "They are doing something that I'm going to do. I have to listen to them." Not everyone agreed with her. Takashi and Andres thought it was funny to watch their classmates act out role-plays. Takashi commented, "It's funny and interesting because there are many different situations." Andres also found it funny, but he made sure to mention he respected his peers, 'It's a little funny, but I respect them. I don't do anything." However, Fahad viewed role-play activities as an opportunity to make fun of the others in class. He stated, “I don't feel shy or sorry for them. I just make fun of them."

The class observation showed that the audience did not always pay attention to the role-plays. During the observations, I noticed that in most presentations, there were some distracted students. Even though some students mentioned they believed they learned from their classmates or laughed at them, the performances did not seem to be interesting to all the students. This excerpt from my notes illustrates this point:

March 19, 2002, 1:50 p.m. The instructor distributes the role-cards and sets the pairs who are going to work together. "We're going to role-play these situations. I want you to use the expressions we have just learned," explains the instructor. The students start reading the cards. Nasser calls the teacher; he does not understand his situation. Ahmed and Luisa try to understand what is in her card. All the students are talking at the same time now. They are suddenly interrupted 
by the instructor calling on the first pair, Takashi and Fahad. They start talking immediately. Andres, who is sitting across from the pair, looks out the window. The weather is still cold, but the sun is shining today. It's Ahmed and Luisa's turn now. While they are presenting, Diana and Camila are still practicing. They are rehearsing because they are the next pair to present. Yuki is now cleaning her nails. She is completely unaware of what Ahmed and Luisa are saying. Diana and Camila are still talking and disturbing the pair that was presenting. The instructor interferes...

Another interesting feature of this audience is what I have decided to call audience interaction. It's exactly the opposite of the distraction illustrated above. During the performances, some students were so interested in the dialogues being presented that they would interact with the students who were performing; that is, they took part in the dialogue by saying something related to it. In three different instances, a student sitting in the audience managed to contribute somehow to the interaction. The following excerpt from one of the role-plays shows an example of audience interaction:

(2) Luisa - And you were with somebody?

Fahad - Yes. I was with my wife.

Luisa - Yeah?

Camila - Your wife?

Luisa - I didn’t know that!

Fahad - You don't know?

Luisa - That you were married.

Ahmed (in the audience) - Which one? Number three? 
Fahad - Yeah. Number three. (laughs)

Luisa - I don't believe you! It isn't fair! (giggles)

Thus, the audience seemed to be attentive to the role-play enactments because they believed they could learn from their classmates, or because they found it funny. Some students did not seem interested in some performances, though.

Participants' preferences.

The questionnaire revealed that when compared to other more traditional classroom activities, role-plays did not rank as one of the favorites. Actually, five participants classified role-plays as one of their least favorite activities. The students seemed to prefer more mechanical activities such as reading and answering questions, filling in the blanks, and writing compositions. Table 6 shows how the students ranked activities from the most favorite to the least favorite. 
Table 6

Students' Most Favorite (1) and Least Favorite Activities (5)

\begin{tabular}{lccccc}
\hline Students & $\begin{array}{c}\text { Filling in } \\
\text { the blanks }\end{array}$ & $\begin{array}{c}\text { Repeating after } \\
\text { the teacher }\end{array}$ & $\begin{array}{c}\text { Writing } \\
\text { compositions }\end{array}$ & $\begin{array}{c}\text { Reading and } \\
\text { answering } \\
\text { questions }\end{array}$ & $\begin{array}{c}\text { Role-playing } \\
\text { situations }\end{array}$ \\
\hline Diana & 4 & 3 & 2 & 1 & 5 \\
Luisa & 1 & 2 & 3 & 4 & 5 \\
Camila & 4 & 3 & 1 & 2 & 5 \\
Andres & 1 & 2 & 4 & 5 & 3 \\
Nasser & 3 & 5 & 2 & 1 & 4 \\
Ahmed & 5 & 1 & 2 & 4 & 3 \\
Fahad & 1 & {$[3]$} & 5 & 4 & 1 \\
Takashi & 1 & 5 & 3 & 2 & 4 \\
Yuki & 3 & 5 & 4 & 2 & 1 \\
\hline
\end{tabular}


Even though role-play activities were not considered one of their favorite activities, eight participants affirmed they wanted to continue having role-plays in their ESL classes. Luisa was the only participant who said the opposite.

In brief, this category presented the data related to three distinct areas. First, the way the participants felt during role-plays was described. The feelings students reported experiencing included shyness, nervousness, embarrassment, and fear of failure. Next, issues related to the audience were discussed. These issues comprised audience distraction, audience interaction, and the way the participants reacted to their classmates' performances. Finally, the participants' preferences towards classroom activities were reported. Although most students do not consider role-plays as their favorite activity, they found it beneficial to continue having role-plays in their English classes.

\section{Other Considerations}

The relationship between the instructor and the group of students is another key factor for the understanding of the findings. As mentioned earlier in this chapter, the instructor in charge of the group is an experienced native speaker ESL teacher, who has very special personal traits. Judy is a fun-loving person, who is funny and sometimes ironic. She was friendly and easygoing most of the time, but not lenient. She always had total control over her students in a very respectful manner. In addition, she is very much aware of cultural differences, especially because she was an exchange student herself. There was an excellent rapport between the instructor and her students. By observing the class, I was able to notice that they had a great connection. As Judy mentioned, "This class became family." The following excerpt from my notes illustrates the excellent rapport between the instructor and the students. 
It's $12: 53$ and the teacher is alone in the classroom. She places her books, copies and pens on her desk. She sits down. Luisa and Camila enter the room, "Hi, how are you? We are 5 minutes earlier." The teacher smiles and says jokingly, "I've never seen this before." The students come in one by one. They all greet the instructor, who replies with a different comment to each student. Nasser comes in and says, "You look nice. This color is good to you." The instructor replies flattering the student, "Thanks my best student." She continues, "Is Andres missing today?" Diana quickly says, "He is probably still driving." Andres had to go to Florida to visit his family. The class laughs. The teacher asks the students what they are planning to do for the Foreign Festival. Everybody has an idea. Fahad wants paper to write Arabic words. Andres comes in. He stops right in front of the teacher's desk, "Hi Judy." The teacher surprises Andres by saying, "Hi Andres, here is the book you lost." The class laughs because Andres did not know he had lost one of his books.

Because of their great rapport, the participants seemed to feel extremely at ease in class. They were comfortable in that fun and relaxing environment to the point that they would jump and imitate a butterfly in class during a game. The excerpt below illustrates this point.

It's April 18, the last class of the week. "OK, before we all go home, let's play Guesstures," the teacher announces. She quickly divides the class into two groups, which she names "Talkers and Talkers 2," referring to the talkative nature of her students. Diana replies jokingly, “That's offensive!” The teacher answers in the same tone, "You'll have to report me!", and they both started laughing. Five minutes into the game, and it is Andres' turn to perform his mimicry. He jumps, 
sticks his tongue out, and even points to the instructor, but nobody guesses his word. After his time is over, he reveals it, "It's crazy." His revelation makes the instructor wonder why he has pointed at her. Nasser grabs a card and starts to fly like a butterfly...

Although some of the statements used in the class, as exemplified in this excerpt, may sound hostile, it is important to mention that, as an observer, I noticed that the atmosphere in the classroom was great. There is no evidence that any of the students seemed annoyed by the jokes that were made in class by the teacher and students. The students' actions in the passage above show how comfortable they felt in class. This positive atmosphere in class might have contributed to the students' acceptance of the role-play activities proposed by the instructor.

\section{Summary}

The analysis of the data revealed three categories pertaining to the students' perceptions of role-play activities. The benefits of role-plays is one of the categories. The participants identified seven positive aspects of role-plays. They are (a) improving oral proficiency, (b) getting used to speaking, (c) receiving teacher feedback, (d) rehearsing of real-life situations, (e) acquiring new vocabulary, (f) having fun in class, and (g) learning from classmates. The second category deals with the limitations of role-play activities. The four problematic areas include a) lack of vocabulary and ideas, b) animosity between students, c) artificiality of performances, and d) artificiality of the task. The last category is related to the feeling and reactions to role-play activities. The data showed that only one student was completely comfortable during role-plays. The others experienced shyness, nervousness, embarrassment, and fear of failure. However, eight of the participants wanted to have role-plays in their future classes. Other pertinent issues 
include the relationship among the instructor and the students, and the behavior of the audience.

Although the participants are aware of the drawbacks of the activity, there has been a general approval of role-play activities. The unpleasant feelings, which are so connected to the task, do not seem to affect the students' perceptions negatively. In the following chapter, the findings are discussed in more details. 


\section{Chapter 5}

Discussion

Role-plays have provoked a lot of debate and comments. Proponents of the activity, such as Paulston and Bruder (1976) and Littlewood (1981), have advocated for the unique benefits which role-plays have provided to students. However, critics have questioned the effectiveness of the activity as well as its role in CLT. In spite of all of the controversy involving role-plays, the findings presented in the previous chapter reveal that the participants seem to approve of the use of role-plays in the classroom. Although the students pointed out negative aspects of role-play activities, the benefits perceived by the participants outnumber the drawbacks. However, both the negative and the positive aspects identified by the students raise issues of equal importance. The chapter is organized in three sections: the positive aspects, the negative aspects, and other issues.

\section{The Positive Aspects}

As pointed out in the review of the literature, research has shown that teachers and students tend to perceive classroom activities differently (Nunan, 1986; Block, 1994). The findings of the current study showed that the students' perceptions of role-play activities were in some instances very similar to what teachers and researchers expected them to be. One of the perceptions that they share is related to the development of oral skills. Rivers (1981) suggests that role-plays are opportunities for learners to try to use what they have learned in communication situations. Likewise, the instructor of the group believed that "...they [role-plays] are very valuable for taking the rules and the things that you were taught, and that you read about, and utilizing them in quasi real-life situations." Similarly, the participants pointed out that they saw role-plays as a way for 
them to use what they knew to improve their oral proficiency and get used to speaking. According to Ahmed, "you learn how to speak with another people." Like Ahmed, other students also mentioned that role-plays helped them improve their speaking abilities in various ways. They do not view role-plays as an activity that they have to endure for the sake of it. They believe they can profit from this activity by using what they learned to express themselves.

Another benefit of role-plays that the students seemed to be aware of is that they not only have to use the target language to communicate, but they also have to produce language according to the context. Both Fahad and Yuki acknowledged the fact that they have to understand their partner first, and then they have to elaborate an appropriate response. For example, Yuki noted that "I learn speaking and understanding. My partner said to me. I understood, so I answered to him.” Their statements support Ladouse (1982) who believes that role-plays encourage the production of utterances that are unpredictable and generated by the context.

Scarcella and Oxford (1992) commented on the fact that role-plays “...promote a relatively safe, protected situation in which students can make cultural and language mistakes without feeling too threatened" (p. 189). Ladouse (1982), too, mentioned that during role interactions, learners are able to try out the language without risk. The information obtained from the interview and the observation validated the idea of roleplays as a non-threatening situation. In the interview, when Ahmed was asked to describe what he liked about role-plays, he said, "It's something you have to do with your classmate in front of the teacher. The teacher will correct you, no problem if you have mistakes or something like this." Based on his statement, I concluded that Ahmed was not worried about the possible mistakes he could make while role-playing. 
Ahmed was not the only participant that admitted verbally that role-plays did not threaten him. Nasser also commented he was completely comfortable with having to perform in front of the classmates, “It's OK. I don't have any problem about that. I'm comfortable. I think that's OK. I don't have anything problem with that." However, the other seven participants reported experiencing some kind of unpleasant feeling during role-plays. In spite of the fact that the students felt shy, embarrassed, nervous, or even afraid of failing, the observations led me to conclude that the other participants, except for Luisa, shared Ahmed's point of view. Luisa was the only student in class who once complained about doing a role-play. On March 21, as soon as the instructor announced they were going to act out the situations presented in the book, Luisa let out a loud "Oh, no!" Unlike Luisa, the other participants did not show any signs of discomfort when they were asked to stand up and perform for the class. I realize that it is rather difficult to detect signs of embarrassment and nervousness. What I am suggesting is that the awkward feelings that the students reported having were not enough to constrain them. The students might have experienced what Scarcella and Oxford (1992) call facilitating anxiety and not debilitating anxiety. The former refers to a good kind of anxiety that helps keep the students attentive. The latter is a negative kind of anxiety that may harm the learners' performance. Therefore, I believe that eight out of the nine participants viewed role-plays as non-threatening situations in which they could experiment with the target language.

The reasons why students seemed to see role-plays as a non-threatening situation cannot be easily determined. It has been suggested that students are likely to lose their inhibitions and feel more comfortable when they are not playing themselves; that is, when they are representing someone else (Harmer, 1991; Purcell, 1993). However, the 
data obtained in this study were not comprehensive enough to confirm this idea. Even though the role-plays I observed required students to play themselves, as well as to represent someone else, there was no evidence that the students behaved differently in the two kinds of performances. In addition, none of the participants commented that they felt more comfortable when they had to represent someone else. I strongly believe that the positive atmosphere in the classroom was one of the factors that contributed immensely to the students' participation in the role-plays proposed.

One of the most praised features of role-play activities is that they promote cultural understanding to ESL learners (Paulston \& Bruder, 1976; Scarcella \& Oxford, 1992). Among the six role-plays performed in class, three activities did contain relevant cultural information. These activities helped the students complain, express anger and frustration, and persuade people in a U.S. context. For instance, the students learned and practiced how to express anger and frustration using different levels of formality and directness. The purpose of the activity was to enable students to recognize when a person was angry or frustrated and also to express their anger and frustration in a way that was clear and would not make the situation worse. After studying the expressions in the book, the students got to practice by role-playing situations in which they were supposed to complain about something that made them angry or frustrated. The activity might not have meant much to the South Americans and Arabs who are more accustomed to complaining in their cultures. However, the Japanese students, Takashi and Yuki, are used to a very different reality. According to Bannai (1981), Japanese students' orientation is “...toward group success and on individual behavior which emphasizes nonassertiveness, verbal restraint, cooperation, subordination of the individual to the group of interest or obedience to authority" (p. 149). Based on Bannai's statement, it is 
clear that the Japanese students would benefit from role-play by receiving input on the new culture. As previously mentioned, Takashi corroborates this by pointing out the following:

I like that we can have, everybody, my classmates, everybody has a difference thinking, so it's kind of interesting because how they behave. I compare everyone's behavior because I'm in America now, and I don't know. In Japan and America sometimes difference, so I want to learn how they do action.

In the role-play mentioned above, for example, they not only learned how to express anger and frustration, but also that they can do that in America.

Paulston and Bruder (1976), who are proponents of role-play activities, put a lot of emphasis on the cultural aspects of role-plays. They believe role-plays to be a great opportunity to expose learners to the cultural and social rules of the target culture. The observations in this study showed that although three role-plays aimed basically at oral development, the other three contained cultural information. The fact that only one student mentioned he learned about the new culture through role-plays makes me believe that this positive aspect of role-plays may only affect those students whose cultures are completely different from the target culture. It also suggests that the students whose cultures are more similar to the target culture may not perceive the sociocultural differences between the two cultures. Therefore, role-plays may be an important tool to promote cultural understanding; however, this feature may not benefit all of the students.

In the interviews, Diana, Nasser, and Andres mentioned that they believed that the role-plays they did in class were very similar to situations that they were likely to come across in real life. Andres commented that "They [role-plays] are real situations. Maybe some day, you're gonna pass for that." Likewise, Diana explained: 
It's just like the real life. There's time you have to deal with this kind of situation. I think it's the same. You always have to talk with the bus driver; you have to talk with the girl or the guy you are having your lunch; you have to discuss for any problem that you might have in a condition, for example.

The statements of these students seem to support the claim that role-play activities bring reality into the classroom (Littlewood, 1981; Di Pietro, 1983; Scarcella \& Oxford, 1992; Savignon, 1997). Three students, Diana, Camila, and Takashi, mentioned that they found it helpful that role-play prepared them to interact in real-life situations. Takashi stated, “...we learned so many situations on role-play, and it helps me. When I have a real situation, if I already did a role-play about, I think I know like fifty percent how I behave. I know how I act.” The subjects' comments are in accordance with what Raz (1981) observed in her research; that is, "Role-play is perceived by the learner as a rehearsal for real life" (p. 228). In addition, the students' statements seem to contradict Widdowson's (1987) prediction that learners may not be able to transfer what they have learned in class to real contexts.

In the literature related to role-play activities, not much attention has been given to the acquisition of vocabulary during role-play interactions. However, two participants seemed to perceive the acquisition of vocabulary as a positive aspect of the activity. Fahad stated that he liked role-plays because “.... sometimes you learn new words, the vocabulary from the role-plays." Camila also commented that one benefited from roleplays because "You can learn vocabulary and some slangs that people use outside." The class observation validated their statement. As mentioned before, one of the situations that was acted out was about a customer complaining about a dry cleaner's service. In this role-play, Diana had to use the word shrunk, which she had just learned. The word 
was successfully used in class again by other students after Diana had used it during her role-play. Other examples of words learned due to the role-plays were anniversary and maid. These words had to be explained to the students so that they could understand the situation they had to act out. Both words were used appropriately by the students in the contexts that they created. I did not observe the use of these two words in other instances. However, I believe the observation is enough to validate the students' perceptions of roleplays as an activity that promotes vocabulary acquisition.

Receiving corrective feedback from the teacher was another benefit perceived by the students. Three students believed they profited from role-play activities because they were corrected by the teacher. Nevertheless, that was not the instructor's objective in using role-plays. Consequently, she did not correct the students on their role-play performances, but she did correct her students during other oral activities.

During oral interactions, the instructor responded to her students' errors through negotiation of form instead of explicit correction (e.g., "It's not she go; it's she goes."). Lyster and Ranta (1997) defined negotiation of form as “...the provision of corrective feedback that encourages self-repair and precision and not merely comprehensibility" (p. 42). During the observation, I noticed that the instructor opted for types of feedback that allowed for negotiation of form. Her feedback consisted of a) clarification requests (the teacher indicated to the students that a repetition or reformulation was required because their utterances were misunderstood or ill-formed), b) elicitation (the teacher directly elicited the correct form from the student), and c) repetition (the teacher repeated the students' erroneous utterances highlighting the errors) (Lyster \& Ranta, 1997). The instructor also made use of a lot of facial expressions to provide corrective feedback. However, these strategies were not used during any of the role-play performances. 
There are three possible explanations for the fact that the students perceived teacher correction as one of the advantages of role-plays. First, the students may not have realized that the feedback they had during other oral activities was not present in roleplays. They just took it for granted that they would have feedback during any oral activities. Second, the instructor may have provided feedback on the role-plays performed before the class started being observed by the researcher. Finally, the participants may have related teacher correction with negotiation of meaning or teacher feedback, that is, facial or verbal signals provided by the teacher to indicate that she understands what is being said (Richards, Platt, \& Platt, 1992). One of the students who mentioned teacher correction as a benefit, Ahmed, was involved in two instances in which there was negotiation of meaning or elicitation of feedback from the teacher. In one of these situations, he requested confirmation from the instructor as he tried to use a word that he had just heard Diana utter. Just like his classmate, Ahmed said, "You shrunk" (there was a tone of uncertainty in his voice). He stopped for a while, looked at the teacher and repeated, "Shrunk?" After the teacher nodded, he continued the dialogue. In the other instance, negotiation of meaning between nonnative speakers took place. Ahmed, Diana, and Nasser were carrying out a dialogue about Spring Break. The following excerpt of the dialogue shows how the negotiation of meaning occurred.

(3) Ahmed - No, in the day, and it was raining yesterday, the day before. I don't pay attention to the street. I just as usual...

Diana - Are you blind?

Ahmed - Are you what?

Diana - Are you blind? (her hands over her eyes)

Ahmed - No, I was just talking and having fun, and laughing ... 
Thus, it seems that some events that occurred in the classroom may have led students to perceive corrective feedback as one of the positive aspects of role-plays.

\section{The Negative Aspects}

Horwitz (1985) argues that one of the difficulties with traditional role-play activities is their dependence on the quality of individual performances. As a result, the success of the activity may be jeopardized if a student cannot think of anything to say, or if a student has limited acting skills. Two students in this study seemed to share Horwitz's concern. Andres and Takashi pointed out that they worried about not knowing what to say, that is, they were afraid of lacking ideas or vocabulary. As Andres stated, "I have afraid to don't do it well, and maybe get stuck because I start to think, think, think, and the words can't come out." In fact, Yuki had trouble with participating actively in a role-play interaction she carried out with Ahmed and the instructor. She obviously could not think of questions to ask, even though the other two participants tried to include her in the conversation. Although the audience was still attentive, the outcome of the roleplay was quite disappointing. Yuki's poor performance proved that if students are not creative enough, the activity is likely to fail.

Another problem perceived by the participants was the animosity between the students. It seems that other researchers have not come across this kind of problem as I could not find any reference to this issue in the literature. Actually, even the instructor of the class seemed unaware of the problem. She believed the whole group had a great connection. I became aware of the situation because of the qualitative nature of this study. Only after interviewing Diana and analyzing the observations, I realized that some students did not get along well, and this problem seemed to be accentuated when they had to do role-plays together. As mentioned before, in one of the role-plays, Diana took 
advantage of her role to embarrass and put Nasser down (Appendix F). In addition, Ahmed reported that, sometimes, students took things personally, and they could not agree with each other during the interactions. The situation bothered not only the students who did not get along well, but also some students who were observing the role-plays. In this group of students, it appeared that Nasser, who is an older conservative Arab male, did not get along with his younger South American female classmates. Although they were not hostile to one another, and there was no obvious conflict in class, their relationship was basically non-existent. They interacted with one another when they had to do group work. The only female that seemed really annoyed by the situation was Diana, who explicitly said she had problems with one of her classmates. She mentioned that she did not like his macho attitude. Nasser did not complain about any of the women; however, his behavior led me to believe that he was not very fond of Diana. For instance, when Diana was doing an oral presentation, Nasser did not look at her at all. He kept reading a newspaper. When she finished her presentation, he calmly folded the paper and started participating in class as usual. Interestingly, the women did not seem to have any problems with the other two Arab students, who were younger. As a matter of fact, the relationship of these younger males with their female peers was excellent. They often had lunch together before class and went out at night to popular student hangouts.

One of the critics' main concerns about role-play activities is related to the artificiality inherent to the task (Scarcella, 1979; Taylor, 1982; Piper \& Piper, 1983). The artificiality of the activity is present in the language the students produce, the roles and situations assigned, and the audience, which is not part of most communicative situations in the real world. Even though students pointed out some differences between role-plays and real-life interactions, they did not mention issues related to the roles and the 
situations assigned or to the audience. One of the differences the students mentioned was practicing before performing the role-play. However, the most important difference the students perceived was that during role-plays, they did not behave the way they did in real life; they had to act.

Camila, Fahad, and Luisa were aware that during role-play interactions they were performing for their classmates; therefore, their behavior and language were different. Luisa mentioned that doing role-plays was equivalent to acting, "You have to act; put your body in front of all the people and express and talk to them, I mean, for them. You have to speak loud." Camila also pointed out that having to express feelings or portray characters required her to behave unnaturally. She said, "When you are not in a real situation, you have to do some intonation or some expression that if you are in the real moment, you can't do it." Fahad was another student who mentioned that the way he acted during role-plays was different. In this case, Fahad could not avoid taking advantage of being on stage to entertain his classmates. Since he knew that he was performing, he did not bother making the interaction look real. He commented, "We didn't make it real because we laugh in the role-plays, and sometimes we make jokes for the person who is standing...Y You don't laugh, you don't look around when you talk [in real-life situations]." Since they knew they were performing, these students admitted that the behavior and the language they produced did not reflect reality. This notion corroborates what Scarcella (1979) and Taylor (1982) suggest about the language produced during role-play. These authors believe that students fail to produce the language teachers expect, that is, the language they would use in real-life situations.

Although some students acknowledged the artificiality of their performances, the results of this study revealed that some participants saw role-plays as a way of developing 
sociolinguistic competence. They believed role-plays provided them with the knowledge and practice they needed to interact in real-life situations. Some students reported they learned how to behave and act in different situations. One Japanese student even mentioned he got insights into American culture. However, studies have shown that ESL learners lack sociolinguistic competence. Porter (1986) suggests that “ “...learners cannot provide each other with the accurate grammatical and sociolinguistic input that native speakers can provide them" (p. 220). In her investigation of students' interactions during problem-solving activities, Porter found that there was lack of appropriate use of language. Hull (1986) also noticed that the students' interaction during role-play activities showed little evidence of sociolinguistic competence. According to Hull, only a few utterances were clearly appropriate. The findings of the current study corroborate Hull's and Porter's (1986) findings. The students themselves admitted that they did not behave the same way in role-plays and in real life. Therefore, the unnatural behavior they produce is likely to contain little evidence of sociolinguistic competence. The following examples show the students' lack of sociolinguistic competence. Certain sentences they produced are inappropriate, and others are clearly nonnative-like.

(4) Luisa - Oh really! What do you like?

Takashi - What I like?

Fahad - What do you need to know; he is working in the garden.

Luisa - Shut up!

Takashi - What do you mean what I like?

Luisa - I mean, what do you like to do in the house.

(5) Fahad - I told you. He has to work in the garden.

Luisa - Well, you can work in the garden? 


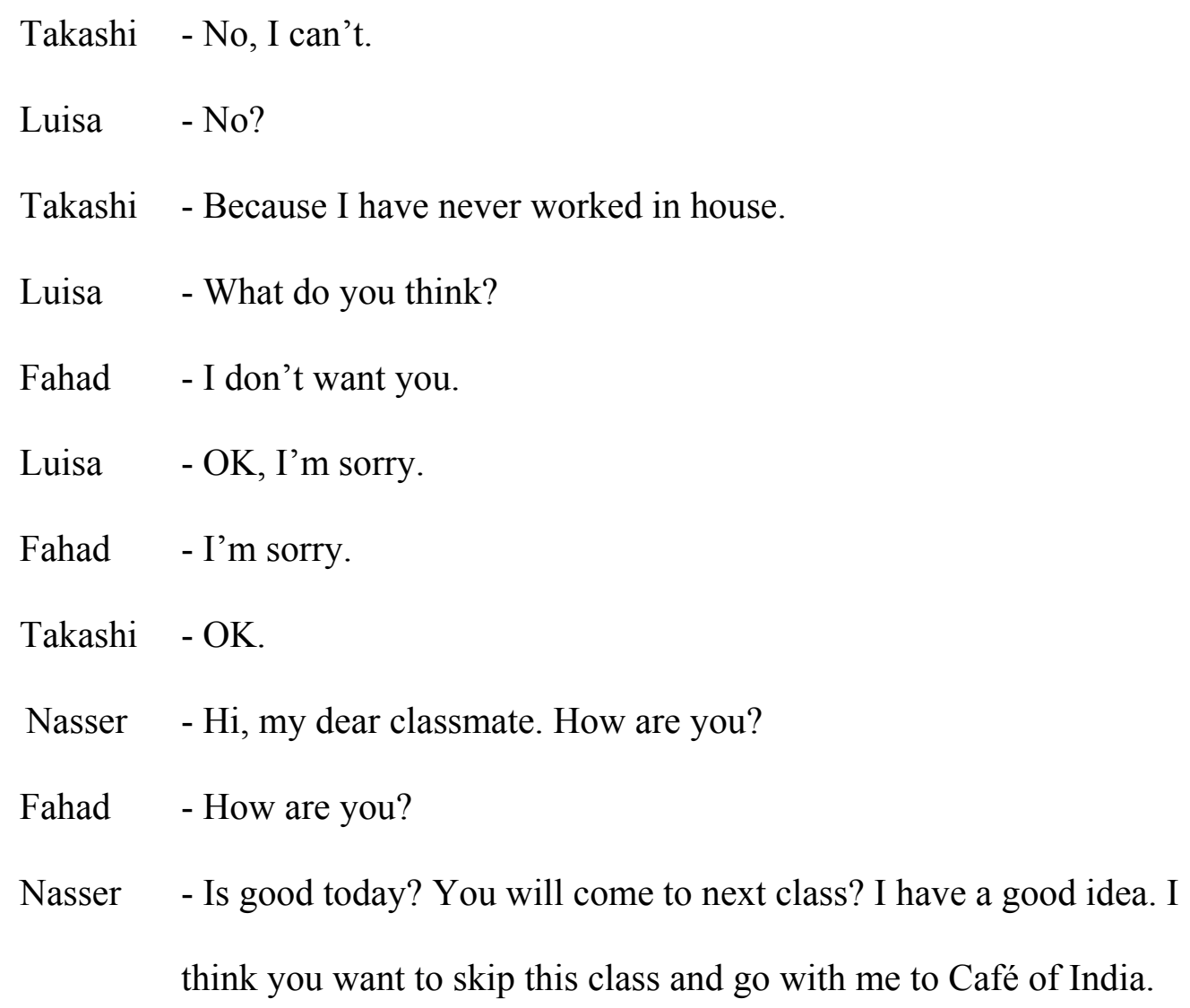

In example (4), a diplomat and his wife were interviewing a college graduate to work in their home. As the husband tried to give his opinion, the wife said, "Shut up!" In example (5), the same couple is getting to the end of the interview. When they decided that the candidate was not suitable for the position, the husband said, "I don't want you." Finally, in example (6), a student greeted his classmate by saying, "Hi, my dear classmate. How are you?" All of these examples are clear indications of a lack of sociocultural awareness of appropriate language use.

One of the purposes of role-play activities is to develop communicative competence by bringing the outside world into the classroom (Littlewood, 1981) and exposing students to the diverse registers they need to know (Scarcella \& Oxford, 1992). However, since some students did not perceive role-plays as real-life situations, and consequently did not behave as they would in reality, it seems that the activity is not 
serving its purpose of developing communicative competence, or at least one of its aspects. The development of sociolinguistic competence that was perceived as a benefit by the students cannot be properly achieved if learners do not produce appropriate language and behavior. Therefore, the findings for this class reveal that developing sociolinguistic competence through role-plays may require added instruction.

A good solution to the problem mentioned above would be to add a session after role-play interactions so that students can analyze miscommunication and the reasons why it occurred. Since the students perceive artificial behavior as a negative aspect of role-play activities, the debriefing session should not be limited to analyzing miscommunication only. It would be the perfect time for students and teachers to discuss what was artificial in each presentation. Besides analyzing behavior and language that would not be appropriate in real-life situations, cultural issues should also be touched upon.

I find it important to mention that after criticizing some features of role-plays, some students seemed to be accepting of the negative aspects of the activity they had just pointed out. For instance, after Takashi mentioned that he did not like when he did not have ideas or vocabulary to carry out the task, he said, "But I can gesture, so I gesture sometimes." In another instance, he explained that one's partner's level of proficiency may cause the interaction to be artificial. He concluded his idea saying, “...But if the person doesn't ask many things, it's not real action; but it helps me." When Camila complained about having to change her intonation and express feelings that were not real, she wrapped up her ideas saying, “...but it’s OK.” Camila later said, "I feel shy, but I can handle it." Examples like these make me believe that even though the students are aware 
of the drawbacks of role-play activities, they seemed to be pleased with what the activity did have to offer them, that is, language improvement.

\section{Other Issues}

The audience, which is part of every role-play, has been the focus of a lot of criticism. Although Paulston and Bruder (1976) believe the audience affects role-plays positively, others see it as a drawback. For instance, Robinson (1981) finds it difficult to involve the rest of the class while a small group of learners act out their roles. Al-Arish (1994) claims that the audience stresses the artificiality present in role-plays. Besides, he believes the audience inhibits the interaction. In the present study, the audience played two very distinct roles.

The observations showed that oftentimes some students did not pay attention to all role-play enactments. In my notes, there are passages that describe students looking out the window, playing with their nails and hair, and yawning during role-plays. Most of the time, Andres was one of them. In the interview, he said, "Sometimes I get bored in class. I start to fall asleep in class. I need coffee." However, their lack of attentiveness to role-plays was not any different from their response to other activities proposed by the instructor. For instance, it was very common to observe the same kind of attitude that the students had during role-plays when they were doing listening activities, group work, pronunciation exercises, and other tasks.

On the other hand, four students reported that they were very attentive to their classmates during role-plays. Ahmed and Andres believed they could learn from their classmates' performances. In this case, the data obtained from the observations contradicted that data provided by the interviews since Andres did not seem very attentive in class but said he learned from his classmates' performances. In addition, four 
participants mentioned that they believe they could learn from their classmates' mistakes. As Andres pointed out, "I try to correct them. I try to correct them, so I can learn about that." However, the main example of learning did not come from the mistakes produced during role-plays. After Diana used the word shrunk in one of the role-plays, two other students used the same word in class. Therefore, Smith's (1986) belief that during roleplays the audience basically is left to listen to the ungrammatical sentences produced by the small group that is presenting does not seem to be shared by the participants. This group of students believed that they could profit from the role-play performances even if their classmates made mistakes.

Another interesting fact about the audience was that they took part in the role-play enactments. For example, in one of the situations performed, Fahad was trying to persuade Luisa to lend him money so that he could buy airplane tickets to Saudi Arabia for him and his wife. Andres, who was a member of the audience, took part in his peers' conversation by saying, “What about the childrens?" Luisa acknowledged his question and asked Fahad how many children he was planning to take with him. Although it has been observed that some students seemed sometimes unaware of the events going on in class, this audience interaction proves that other students were very interested in the enactments. It also proves that not all audiences are passive, as Al-Arish (1994) predicts.

The roles assigned to the students have also been blamed for the failure of roleplay interactions. Piper and Piper (1983) suggest that the outcome of an interaction can be even more disappointing if the students are not assigned roles they are likely to assume in everyday life. Likewise, Al-Arish (1994) and Piper (1984) point out that most role-plays are unsuccessful because the roles assigned do not reflect the learners' experiences and needs. However, when the students were questioned about the 
difficulties they had doing role-plays, none of them mentioned that the roles assigned to them made the task more difficult. Takashi and Andres both said that sometimes it was difficult to express themselves because they lacked ideas or vocabulary. Following these comments, I asked them if the roles they had to play made any difference. Both gave me a negative answer. Unlike the participants in this study, the EFL students that took part in Su's (1990) research project pointed out that role-playing certain roles was difficult. Su also found that the noise level and the fact that more advanced students monopolize most speaking opportunities were considered disadvantages of role-plays. Her findings were not corroborated by the results of the current study.

In addition, Al-Arish (1994) claims that students resist assuming roles that do not reflect their reality. Most of the role-plays I observed required students to pretend they were roommates, classmates, or friends. However, the participants also had to play a McDonald's cashier, a bank clerk, a landlord/landlady, a dry cleaner, and a diplomat. Even though these roles were far removed from the participants' reality, not one student refused or even complained about assuming any of these roles. It seems that the participants share Littlewood's (1981) point of view. In his opinion, the language that learners practice when they act out less relevant roles is still important.

I would like to comment on the great difference between the activities students experienced in the ESL and the EFL environments. Table 2 shows that in the EFL environment, students are exposed to more traditional methods of language teaching. In fact, the Arabs and the Japanese do not seem to have any kind of activities that entail classroom interaction. On the other hand, Table 3 shows that the ESL environment seems to focus on more communicative activities. Traditional activities, such as drills, still play 
a role in the ESL teaching process, though. This fact raises the question whether similar findings would be found in an EFL setting.

Finally, Table 6 shows that, in spite of the participants' need to develop communication skills, they tend to prefer more traditional activities rather than roleplays. Nevertheless, they seem to perceive role-plays as an important contributor to their language development since all the students considered the activity to be helpful. Besides, eight out of the nine students wanted to continue having role-plays in their English classes. 


\section{Chapter 6}

Conclusion

The purpose of this research project was to investigate ESL learners' perceptions of role-play activities. Since the introduction of CLT in the 1970s, role-plays have been used extensively to help students develop communicative competence. In spite of all the discussion of the benefits and drawbacks of role-plays found in the related literature, it seems that not much attention has been given to the learners' views. Therefore, the objective of this study was to determine how ESL learners perceive the use of role-plays in the classroom and in what ways they believe role-plays facilitate interaction outside of the classroom. Since the focus of the research was on the students' perceptions of roleplay activities, a qualitative research design seemed more appropriate. The three datagathering methods used in the study included a questionnaire, teacher and student interviews, and class observations. The analysis of the data revealed three categories: a) the benefits of role-plays, b) the limitations of role-plays, and c) the feelings and reactions to role-plays.

The data showed a general approval of role-play activities by the participants. Even though the students were aware of some of the limitations of the activity, all of them considered the activity to be helpful. The students provided plenty of reasons to explain how role-plays helped them. One of these reasons was the development of oral skills. The participants believed that role-plays were beneficial because through roleplays they improved their oral proficiency and got accustomed affectively to speaking in the target language. They also recognized that in role-plays, they had to produce language according to the context, which involved understanding their partners and elaborating 
appropriate responses. In addition, the participants pointed out that they acquired vocabulary during role-play activities.

The participants also seemed to relate role-play enactments to situations they were likely to experience in real life. Some participants reported that they believed that the situations acted out in class were very similar to everyday events such as talking to a person with whom you are having lunch, talking to a bus driver, or complaining about something. These participants claimed that role-plays prepared them for interacting in the real world. They believed that they were taught how to behave and carry out conversations in different situations during role-plays. The participants seemed to view role-plays as a rehearsal for real-life situations.

Despite considering the activity helpful in the development of their second language, the students were assertive in pointing out the limitations of the activity. The lack of ideas and vocabulary was one of the problems they had with role-play activities. The students were concerned about not being able to carry out the activity because they lacked the necessary vocabulary and/or ideas, which would eventually cause a breakdown in communication. However, this perception was not corroborated by the observations. In fact, among the 27 role-play enactments, there was only one problematic performance because of a lack of vocabulary and/or ideas.

The participants also pointed out the animosity between some students as a drawback of the activity. Some students felt uncomfortable when classmates that did not get along well had to role-play situations together. However, the most important drawback that was perceived by the students was the fact that during role-plays they did not behave the way they did in real-life situations. The participants admitted that during role-play enactments, their actions as well as the language they used did not reflect their 
real behavior. Some attributed it to the fact that they have to pretend they were in a fictitious situation; therefore, they had to express feelings and take actions to convey to the other students what their role-cards proposed. The fact that students perceived roleplay enactments as acting, and consequently did not behave naturally, is probably the most significant finding in relation to implications for the classroom.

Another negative aspect of role-plays is related to the feelings students claimed they experienced when they had to role-play. Not surprisingly, shyness, embarrassment, nervousness, and fear of failure were the negative feelings the participants mentioned they had during the activity. However, only one student showed signs of dissatisfaction as the teacher proposed a role-play. The other eight participants, on the contrary, never seemed reluctant to engage in the activities. Therefore, it appears that these unpleasant sensations are not enough to prevent the students from taking part in role-play activities.

The results of this study reveal an interesting aspect on the issue of audience in role-play activities. Although signs of boredom and inattentiveness were detected in the audience during role-play enactments, apparently the participants in this study seem to benefit from being part of the audience. Several students mentioned that they believed they could learn from their classmates' performances, even though their classmates made mistakes. They reported that correcting their classmates was a strategy they used to improve their own skills. Based on the observations and the interviews, I concluded that when the students mentioned correcting their classmates, they meant repeating the correct forms mentally. Moreover, two students mentioned that role-plays added some fun to the class. The observation showed that the participants were attentive to the performances so much so that they even interacted with the classmates who were performing. 
Although the students did not consider role-plays as one of their favorite activities, they seemed very accepting of it. Apparently, this general approval of role-play activities can be attributed to two factors. First, the students expressed a need to communicate and function in the ESL environment. Eight out of the nine students that took part in the study intended to go to an American university. In the interviews, these participants expressed a strong desire to develop their communication skills. Therefore, these students were highly motivated since they had to fit into a new community in the near future. The one student that did not have plans to enter an American university was the only one that showed unwillingness to engage in role-play activities. Apparently, she was not as motivated as her classmates. Second, the atmosphere created by the instructor in class was ideal for learning. The students saw their instructor as a peer, someone that was in class to help them achieve a goal. However, the instructor was not lenient, and she managed to show her authority without threatening the students, who seemed to feel safe in that classroom environment.

\section{Implications}

The results of the present study reveal some important implications for teaching. It seems that some students perceive role-plays as a rehearsal for real life and a source of cultural input. However, studies have shown that students do not develop sociolinguistic competence during classroom interaction (Hull, 1986; Porter, 1986). Therefore, they might not be receiving the right input or preparation since most learners' interactions in class indicate lack of appropriate language use. The findings provide evidence that teachers need to be aware of the fact that explicit presentation of accurate forms to develop sociolinguistic competence is needed. In addition, as stated before, learners know they are performing for their classmates; therefore, they do not produce real behavior. 
That is, the students tend to behave unnaturally, which would certainly seem inappropriate in a real context.

Scarcella and Oxford (1992) suggest that teachers add a debriefing session after role-play interactions so that miscommunication and the reasons it occurred could be analyzed. The findings of this study would suggest that a debriefing session after roleplay activities might be extremely important. In these sessions, which include exchange of questions and answers about the target language based on what the learners have attempted to produce (Di Pietro, 1987), the teacher and the students would have the chance to analyze the behavior and the language produced during the enactments. They should determine what was acceptable and what was artificial. Thus, students would get better models, and they could then develop more accurate sociolinguistic competence. In addition, the cultural differences between the target culture and the students' cultures should be explicitly explored during the debriefing sessions since some students do not seem to perceive these differences.

Another important implication is related to pairing students during role-plays. Some students may not get along very well, and this situation may go unnoticed by the teacher. However, it seems that students felt rather annoyed by taking part in interactions with classmates with whom they did not have a good relationship. Even observing this kind of interaction seems troublesome. Therefore, teachers should be vigilant and careful about whom they group together for a role-play.

Although the audience in this study seemed to be attentive to most role-play interactions, the observations showed that some students did not pay attention to some enactments. One of these participants even mentioned in the interview that sometimes he felt bored in class. To avoid this situation, teachers should try to make students in the 
audience accountable. A suggestion is to have each student write on an index card one thing he/she learned from the interaction and also a suggestion to the group that performed the situation. In this way, all the students would be involved in the activity, instead of only the small group who is acting out a role-play situation.

The results of the study also show that, although the critics have pointed out that role-plays may not be as effective as the proponents of the activity suggest, the participants believed they could benefit from role-play activities. Therefore, if the students believe role-plays can help them develop their language skills, teachers should not avoid the use of the activity in the classroom. However, a debriefing session after role-plays is advised to ensure the acquisition of proper language and behavior.

\section{Limitations}

The qualitative design of the study posed two limitations. First, this research relied on the honesty and accuracy of the participants' answers to the questionnaire and the interviews. Second, the students' response to the interviews might have been limited by the participants' English language skills. Since the interviews were conducted in English, it is very likely that the depth and breadth of the students' answers were limited by their language proficiency.

\section{Suggestions for Future Research}

This study suggests several research possibilities. One project would be conducting similar studies with different participants in order for the results of the current study to be corroborated. Since mismatches between teachers' and students' views of classroom activities are likely to influence their effectiveness, investigating the learners' perceptions is needed. However, the present study looked at nine participants only, and the results cannot be generalized. It would also be interesting to learn if similar results 
would be obtained in an EFL setting. Also, it is not clear if different types of implementation would affect the students' perceptions of role-plays. In addition, it could be investigated if learners are really able to transfer what they learn during role-plays to real contexts, as they believe they can. This question would require a meticulous investigation similar to the one carried out by Wilkinson (1998), who observed her participants interacting in real-life situations. Furthermore, there does not seem to be much research on the acquisition of vocabulary during role-play activities. Considering that the participants in this study perceived the acquisition of vocabulary as a benefit of role-plays, I believe that this topic should be further investigated. Finally, another area that seems to require more investigation is the effects of roles on the students' performances. Do students behave differently when they are representing somebody else and not themselves? These are some of the issues that emerged from the results of this study that could lead to further research.

In conclusion, the results of this study have shown that, in spite of some drawbacks, the participants perceived the use of role-plays positively. Their perceptions revealed important implications about the development of communicative competence through role-play activities. Therefore, these results should be taken into account to aid both teachers and students in the language acquisition process. 


\section{Works Cited}

Abraham, L. B. (1996). The use of role-play tasks in an intermediate-level university Spanish class. Unpublished master's thesis, Arizona State University.

Al-Arish, A. Y. (1994). Role-play, real-play, and surreal-play in the ESOL classroom. ELT Journal, 48, 337-346.

Bachman, L. (1990). Fundamental considerations in language testing. Oxford: Oxford University Press.

Bannai, H. (1980). Social-cultural influence on the communication development of ESL students. On TESOL ' $80,147-158$.

Block, D. (1994). A day in the life of a class: teacher/learner perceptions of task purposes in conflict. System, 22, 473-486.

Boardman, R. (1979). Over to you. Cambridge: Cambridge University Press.

Canale, M., \& Swain, M. (1980). Theoretical bases of communicative approaches to second language teaching and testing. Applied Linguistics, 1, 1-47.

Canale, M. (1983). From communicative competence to communicative language pedagogy. In J. Richards \& R. Schmidt (Eds.), Language and communication (pp. 2-27). New York: Longman.

Di Pietro, R. (1981). Discourse and real-life roles in the ESL classroom. TESOL Quarterly, 15, 27-33.

Di Pietro, R. (1982). The open-ended scenario: A new approach to conversation. TESOL Quarterly, 16, 15-20.

Di Pietro, R. (1983). Scenarios, discourse, and real-life roles. In J. W. Oller \& P. A. Richard-Amato (Eds.), Methods that work: A smorgsbord of ideas for language teachers (pp. 226-237). Rowley: Newbury House Publishers. 
Di Pietro, R. (1987). Strategic interaction: Learning languages through scenarios. Cambridge: Cambridge University Press.

Di Pietro, R. (1990). Roles in foreign language classroom. In A. Labarca \& L. M. Bailey (Eds.), Issues in L2: Theory as practice/practice as theory (pp. 1-9). Norwood, N.J.: Ablex Publishing Corporation.

Ducroquet, L. (1991). Role-play: An assessment. Language Learning Journal, 3, 49-50. Errington, E. (1997). Role-play. Jameson Centre, Australian Capital Territory: Higher Education Research and Development Society of Australasia Incorporated.

Fragiadakis, H. K., \& Maurer, V. M. (1995). Sound ideas: Advanced listening and speaking. Boston, MA: Heinle \& Heinle Publishers.

Fragiadakis, H. K. (1997). All clear: Advanced idioms and pronunciation in context. Boston, MA: Heinle \& Heinle Publishers.

Gass, S. M. \& Varonis, E. M. (1989). Incorporated repairs in nonnative discourse. In M. R. Eisenstein (Ed.), The dynamic interlanguage. New York: Plenum Press (pp. 71-86).

Gass, S., Mackey, A., \& Pica, T. (1998). The role of input and interaction in second language acquisition. Modern Language Journal, 82, 299-307.

Guntermann, G. (1980). Factors in targeting proficiency levels and an approach to "real" and "realistic" practice. Studies in Second Language Acquisition, 3, 34-41.

Harmer, J. (1991). The practice of English language teaching. New York: Longman. Holden, S. (1981). Drama in language teaching. Harlow, England: Longman.

Horwitz, E. (1985). Getting them all into the act: Using audience participation to increase the effectiveness of role-play activities. Foreign Language Annals, 18, 205-208.

Howatt, A. (1994). A history of English language teaching. Oxford: Oxford University Press. 
Hull, J. (1986). Role play activities in second language teaching: Development, implementation and evaluation. Unpublished master's thesis, University of Hawaii.

Hymes, D. (1972). On communicative competence. In J. B. Pride \& J. Holmes (Eds.), Sociolinguistics: Selected readings (pp. 269-293). Baltimore: Penguin.

Jones, K. (1982). Simulations in language teaching. Cambridge: Cambridge University Press.

Kamaravadivelu, B. (1991). Language learning tasks: Teacher intention and learner interpretation. ELT Journal, 45, 98-107.

Kozyrev, J., \& Baker, M. (2201). Talk it through! Boston: Houghton Miffin Company. Ladousse, G. (1982). Role play and simulation in language learning. Simulation/Games for Learning, 12, 51-60.

Lee, J. \& VanPatten, B. (1995). Making communicative language teaching happen. New York: McGraw-Hill, Inc.

Littlewood, W. T. (1981). Communicative language teaching: An introduction. Cambridge: Cambridge University Press.

Long, M. H. (1996). The role of linguistic environment in second language acquisition. In W. C. Ritchie \& T. K. Bhatia (Eds.), Handbook of second language acquisition ` (pp. 413-468). New York: Academic Press.

Lyster, R. \& Ranta, L. (1997). Corrective feedback and learners uptake: Negotiation of form in communicative classrooms. Studies in Second Language Acquisition, 19, $37-66$.

Maley, A. (1980). Teaching for communicative competence: Reality and illusion. Studies in Second Language Acquisition, 3, 10-16. 
Marshal, C., \& Rossman, G. B. (1999). Designing qualitative research ( ${ }^{\text {rd }}$ ed.). Thousand Oaks, CA: SAGE Publications.

Nunan, D. (1986, April). Communicative language teaching: The learner's view. Paper presented at RELC Regional Seminar, Singapore.

Nunan, D. (1988). Syllabus design. Oxford: Oxford University Press.

Paulston, C., \& Bruder, M. (1976). Teaching English as a second language: Techniques and procedures. Cambridge, MA: Winthrop Publishers.

Paulston, C. B. (1985). Communicative competence and language teaching: Second thoughts. Selected papers from the RELC Seminar, Singapore, 84, 13-29.

Piper, D., \& Piper, T. (1983). Reality and second language role-play. The Canadian Modern Language Review, 40, 82-87.

Piper, T. (1984). Putting reality into role-play. TESL Canada Journal, 1, 29-34.

Porter, P. (1986). How learners talk to each other: Input and interaction in task centered discussions. In R. R. Day (Ed.), Talking to learn: Conversation in second language acquisition (pp. 200-222). Cambridge: Newbury House Publishers.

Purcell, J. M. (1993). Livelier FLES lessons through role-play. Hispania, 76, 912-918. Raz, H. (1985). Role-play in foreign language learning. System, 3, 225-229.

Richards, J. C. (1980). Conversation. TESOL Quarterly, 14, 413-431.

Richards, J. C., Hull, J., \& Proctor, S. (1997). New Interchange: English for international communication: Students’ book 2. Cambridge: Cambridge University Press.

Richards, J.C., Platt, J., \& Platt, H. (1992). Dictionary of language teaching and applied linguistics (2 ${ }^{\text {nd }}$ ed.). Essex, England: Longman.

Richards, J. C., \& Rodgers, T. (1986). Approaches and methods in language teaching. Cambridge: Cambridge University Press. 
Richards, J. C., \& Rodgers, T. (2001). Approaches and methods in language teaching ( $2^{\text {nd }}$ ed.). Cambridge: Cambridge University Press.

Rivers, W. (1973). From linguistic competence to communicative competence. TESOL Quarterly, 7, 25-34.

Rivers, W. (1978). A practical guide to the teaching of English as a second or foreign language. New York: Oxford University Press.

Rivers, W. (1981). Teaching foreign language skills (2 ${ }^{\text {nd }}$ ed.). Chicago: The University of Chicago Press.

Robinson, P. G. (1981). Role-play and classroom participation. ELT Journal, 35, 384-386.

Rodriguez, R., \& White, R. (1983). From role-play to real world. In J. W. Oller \& P. A. Richard-Amato (Eds.), Methods that work: A smorgsbord of ideas for language teachers (pp. 246-258). Rowley: Newbury House Publishers.

Savignon, S. J. (1972). Communicative competence: An experiment in foreign-language teaching. Philadelphia: Center for Curriculum Development.

Savignon, S. J. (1983). Communicative competence: Theory and classroom practice. Reading, Massachusetts: Addison-Wesley Publishing Company.

Savignon, S. J. (1997). Communicative competence: Theory and classroom practice ( $2^{\text {nd }}$ ed.). New York: McGraw-Hill.

Scarcella, R. (1978). Socio-drama for social interaction. TESOL Quarterly, 12, 41-46.

Scarcella, R. (1979). On speaking politely in a second language. On TESOL '79, 275-287. 
Scarcella, R. C., \& Oxford, R. L. (1992). The tapestry of language learning: The individual in the communicative classroom. Boston, MA: Heinle \& Heinle Publishers.

Schmidt, L. (1985). The elements of successful role-play in adult English as a second language. Unpublished master's thesis, University of California, Los Angeles.

Scullard, S. (1986). Teaching speaking skills: from role-play to communicative competence via information-gap and opinion-gap activities. One teacher's approach. The British Journal of Language Teaching, 24, 83-86.

Smith, F. L. (1986). Is role-play an effective EFL technique? WATESOL Working Papers, 3, 10-18.

Stern, S. (1980). Drama in second language learning from a psycholinguistic perspective. Language Learning, 30, 77-97.

Su, P. C. (1990). The effectiveness of role-play activities in learning English as a foreign language by Chinese college students. Unpublished doctoral dissertation, The University of San Francisco, California.

Surplus, S. (1983). Overcoming role-play resistance. Training, 20, 93-97.

Taylor, B. P. (1982). In search of real reality. TESOL Quarterly, 16, 29-42.

Taylor, B., \& Wolfson, N. (1978). Breaking down the free conversation myth. TESOL Quarterly, 12, 31-39.

Widdowson, H. (1987). Aspects of syllabus design. In M. Tickoo (Ed.), Language syllabuses : State of the art (pp. 65-89). Singapore : Regional English Language Center.

Wilkinson, S. (1998). Study abroad from the participants perspective : A challenge to common beleifs. Foreign Language Annals, 31, 23-39. 


\section{Appendix A}

These activities are examples of the activity continuum proposed by Littlewood. All the following examples are taken from the book Communicative Language Teaching, by Littlewood (1981).

1. Role-playing controlled through cued dialogues

Learner A

You meet B in the street.

A: Greet B.

B:

A: Ask B where he is going.

B:

A: Suggest somewhere to go together.

B:

A: Accept B's suggestion.

B:

2. Role-playing controlled through cues and information

Student A: You arrive at a small hotel one evening. In the foyer, you meet the manager(ess) and:

Ask if there is a room vacant.

Ask the price, including breakfast.

Say how many nights you would like to stay.

Ask where you can park your car for the night.

Say what time you would like to have breakfast. suggestion

A:
Learner B

You meet $\mathrm{A}$ in the street.

A:

B: Greet A.

A:

B: Say you are going for a walk

A:

B: Reject A's suggestion. Make a different
B: Express pleasure. 
Student B: You are the manager(ess) of a small hotel that prides itself on its friendly, homely atmosphere. You have a single and a double room vacant for tonight. The prices are: $£ 8.50$ for the single room, $£ 15.00$ for the double room. Breakfast is $£ 1.50$ extra per person. In the street behind the hotel, there is a free car park. Guests can have tea in bed in the morning, for 50p.

3. Role-playing controlled through situation and goals

Student A: You wish to buy a car. You are in a showroom, looking at a second-hand car that might be suitable. You decide to find out more about it, for example how old it is, who the previous owner was, how expensive it is to run and whether there is a guarantee. You can pay up to about $\$ 900$ in cash.

Student B: You are a car salesman. You see a customer looking at a car in the showroom. The car is two years old and belonged previously to the leader of a local pop group. It does about twenty miles to the gallon. Your firm offers a three-month guarantee and can arrange hire purchase. The price you are asking for the car is $£ 1,400$.

4. Role-playing in the form of debate and discussion

This is an activity from the book Over to you by Boardman (1979). You are a group of people who are anxious to help the old in your small town, and you have managed to make a start by collecting $£ 1,000$ from local inhabitants and holding jumble sales.

Study your role and then discuss how the money can best be used. 
Student A: Role: Miss Julia Jenkins, spinster.

You feel that you should contact one of the charity organisations advertised on pages 94-95 [of Over to you], at least for advice.

Student B: Role: Rev. Ronald Rix, the local vicar.

You wish to found an Old People's Club which will meet in the church hall. Some of the $£ 1,000$ that has been collected was raised by holding jumble sales in the church hall.

Student C: Role: Mr David Hicks, the headmaster of the local primary school. You are anxious for the pupils at your school to play a role in helping the aged.

Student D: Role: Mrs Dorothy Foster, widow.

You think the money should be used to renovate an old country house which could be used as an old people's recreation centre. 


\section{Appendix B}

Questionnaire

1. What is your name? Please print.

2. Gender: ( ) Male ( ) Female

3. Age: $\quad\left(\begin{array}{llll}\text { ) under } 18 & \text { ( ) } 18 \text { to } 24 & \text { ( ) } 25 \text { to } 32 & \text { ( ) over } 32\end{array}\right.$

4. What country are you from?

5. Indicate highest academic level completed.

( ) high school

( ) university undergraduate degree

( ) university graduate degree (Master's level)

( ) Ph. D.

6. What is your occupation in your country?

7. What language do you speak with your parents?

8. How long have you been studying English?

9. In what countries have you studied English?

10. How long have you been in the USA?

11. What is your most recent TOEFL score?

12. What is your placement in the Intensive English Program (IEP)? ( )3A $\quad(\quad) 3 \mathrm{~B} / \mathrm{C}$ 13. How many hours of English instruction do you currently have per week?

14. Why are you studying English?

( ) interest in the culture

( ) to get a better job

( ) to go to an American university 
( ) to read English language publications

( ) other:

15. Rank the English skills that you are most likely to use in the future?

( ) listening

( ) speaking

$1=$ most likely

( ) reading

$4=$ least likely

( ) writing

16. In what type of school have you studied English? Check all that apply.
( ) high school
( ) private language institute
( ) college
( ) other:

17. How many students were there in class?

high school

college

language institute

other

( ) less than ten

( ) less than ten

( ) less than ten

( ) less than ten

( ) 10 to 15

( ) 10 to 15

( ) 10 to 15

( ) 10 to 15

( ) 16 to 25

( ) 16 to 25

( ) 16 to 25

( ) 16 to 25

( ) more than 25

( ) more than 25

( ) more than 25

( ) more than 25

18. What activities have you had in your English classes in your own country? Check all that apply.
( ) translation
( ) group discussion
( ) drills ( e.g. textbooks exercises)
( ) role-plays
( ) act out commands given by the teacher

19. What activities have you had in your English classes in the IEP? Check all that apply.
( ) translation
( ) group discussion 
( ) drills ( e.g. textbooks exercises)

( ) act out commands given by the teacher

( ) role-plays

20. Rank the activities below from your favorite to the least favorite.

( ) filling in the blanks

( ) repeating after the teacher

( ) writing compositions

( ) reading texts and answering questions

( ) role-playing situations

$$
\begin{aligned}
& 1=\text { most favorite } \\
& 5=\text { least favorite }
\end{aligned}
$$

21. In class, you:

( ) participate a lot.

( ) participate only when the teacher calls on you.

( ) like to express yourself.

( ) prefer listening to the others.

( ) other:

22. How many hours per week do you ...
a. ... watch TV?
b. ... go to the "English Table"?
c. ... talk to your conversation partner?
d. ... read books and magazines in English?

23. How often do you interact with native speakers outside your language school?

$$
\text { ( ) every day }
$$

\footnotetext{
${ }^{2}$ This is an extra curricular activity arranged by the intensive English program where the study was carried out. The purpose is for international students to practice talking informally with proficient/native English speakers.
} 
( ) 3 times a week

( ) 5 times a week

( ) other:

24. Do role-plays help you interact with native speakers in real-life situations?
( ) always
( ) often
( ) sometimes
( ) seldom
( ) never 


\section{Appendix C}

Student Interview

1. What kind of student are you? Describe your personality.

2. Have you ever felt frustrated when talking to a native speaker? If so, what happened?

3. Is it important for you to develop your communication skills? Why?

4. What do you learn from role-play activities?

5. Do you think role-play activities help you? If so, how do they help you?

6. What do you like about role-plays?

7. What do you dislike about role-plays?

8. How do you feel when you are performing in front of your teacher and classmates?

9. How do you feel when your classmates are performing?

10. Do you find it difficult to do role-plays? Why?

11. Do you think role-plays are similar to a real interaction? Why/why not?

12. What can teachers do to help you interact in real-life situations?

13. Do you want to have role-plays in your English classes in the future? 


\section{Appendix D}

Teacher Interview

1. How would you describe (student's name) regarding his or her attitude in the classroom?

2. How would you define a role-play activity?

3. What is your objective when you use role-plays in your lessons?

4. How do students benefit from role-plays?

5. Does the activity (role-play) have any drawbacks?

6. How did role-plays work for this group of students in particular? Is there a reason why?

7. In your opinion, how did the students react to the role-plays they had in class?

8. What do you think they seemed to like the most? Why?

9. What do you think they seemed to like the least? Why? 


\section{Appendix E}

Role-plays utilized

I. Practice expressing anger and frustration constructively. Role-play one of the following scenes with a partner. Use the phrases that you read about previously for interrupting and for expressing anger and frustration.

Scene A: Neighbor One is playing loud rock music from his or her stereo very late on a weeknight. Neighbor Two is in the apartment next door, studying for an exam. Neighbor One: You are having a small party with some friends from out of town, and you think that it is your right to play your stereo as you like. Refuse to turn it down.

Neighbor Two: The loudness of the music is really bothering you. You can't study, and you threaten to call the police.

Scene B: A customer is complaining to a dry cleaner about the way his or her shirt was laundered.

Customer: You claim that the dry cleaner shrunk your favorite shirt and that it's ruined. You insist that the dry cleaner pay for it.

Dry Cleaner: You have asked the customer for a receipt and he or she does not have one. You say that you will not pay because you do not know if your store is responsible for the damage.

Scene C: Two friends agree to meet each other at the movie theater to watch the latest box-office hit.

Friend One: You arrived on time and have been waiting for half an hour. The movie, which you really wanted to see, has started and you are very frustrated 
and angry with your friend because he or she is always late, even when it is important to be on time.

Friend Two: You got stuck in traffic and couldn't find a parking space. You are not really concerned because you didn't really want to see the movie.

This activity was taken from the textbook Talk it through, by Kozyrev and Baker (2001), page 81 .

II. With a partner, choose one of the following ending statements. For each of the situations following the statement that you choose, play short role-plays of four to six lines each. For each situation, end the role-play with the given ending statement. You will need to pronounce the ending statement with different intonation to express different attitudes.

Ending statement A: "Sure. I can do that."

Situation \#1 (neutral): Your classmate asks you to help plan a class party, and you agree.

Situation \#2 (enthusiastic): You've been invited to help your classmates with a school project, and you're very excited to do so.

Situation \#3 (sarcastic): A classmate asks you to do something that you are sure that you cannot do. In fact, you think it is impossible.

Ending statement B: "That sounds like a wonderful idea." Situation \#1 (neutral): A friend tells you about a present that he or she has bought to give to his or her parents. You think it is a nice present. Situation \#2 (enthusiastic): You and a friend are trying to choose a restaurant for 
dinner. After a lot of thinking, your friend suggests a great restaurant that you had forgotten about.

Situation \#3 (sarcastic): Your friend's roommate has a problem. Your friend tells you about how the roommate plans to solve the problem. And it sounds like a bad solution to you.

Ending statement C: "Yeah, I'll be finished on time."

Situation \#1 (neutral): You are writing a proposal for your boss that is due at 5:00 P.M. today. Your boss wants to know when you will finish.

Situation \#2 (enthusiastic): Your boss tells you that you will get a bonus if you are able to finish an important project on time and wants to know if you think you can do it.

Situation \#3 (sarcastic): A coworker tells you that the boss has moved the deadline on the project that you are working on. You know that you can never finish the project on time.

This activity was taken from the textbook Talk it through, by Kozyrev and Baker (2001), page 120 . 


\section{Appendix F}

Situation: A college graduate is looking for a job as a maid. He/she is being interviewed by a diplomat and his wife, who, unlike her husband, does not want to hire the applicant.

Andres - Can I help you?

Nasser - Yeah. I graduated last month and I'm looking for a job.

Andres - So what do you want to do?

Diana - What do you wanna do?

Nasser - My major public administration, so I can stay in your house and I can manage you life: how you can go, and how you can do. I can manage your life.

Diana - Yeah, I know but we need somebody, you know, to clean the house, to ...

Nasser - NO (emphatic).

Diana - Prepare the food...

Nasser - No way. No way

Diana - To take care of the children...

Nasser - No, no, no, no, no. No, I can't.

Diana - I don't know, but if you are here because you want a job...

Andres - He can do...

Diana - I know, but I'm asking him what he is doing...

Andres - He can teach me how to manage the house.

Nasser - Thank you.

Diana - No. We need somebody to prepare the food for us.

Nasser - I think you need the person for same me.

Diana - The problem is that you wanna do that, be a house maid.

Nasser - What? 
Diana -Do you wanna do that? Do you wanna be a housemaid in our house?

Nasser - No.

Diana -OK. See you.

Nasser - You have a job?

Diana - Is enough. (She walks towards her desk)

Nasser - What did you decide. Accept me or no? 